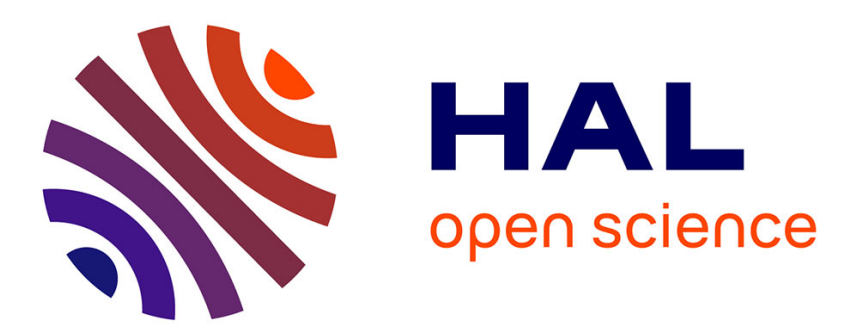

\title{
Ice internal friction: standard theoretical perspectives on friction codified, adapted for the unusual rheology of ice, and unified
}

Daniel Christopher Hatton, Peter R Sammonds, Daniel L Feltham

\section{- To cite this version:}

Daniel Christopher Hatton, Peter R Sammonds, Daniel L Feltham. Ice internal friction: standard theoretical perspectives on friction codified, adapted for the unusual rheology of ice, and unified. Philosophical Magazine, 2009, 89 (31), pp.2771-2799. 10.1080/14786430903113769 . hal-00526549

\section{HAL Id: hal-00526549 \\ https://hal.science/hal-00526549}

Submitted on 15 Oct 2010

HAL is a multi-disciplinary open access archive for the deposit and dissemination of scientific research documents, whether they are published or not. The documents may come from teaching and research institutions in France or abroad, or from public or private research centers.
L'archive ouverte pluridisciplinaire HAL, est destinée au dépôt et à la diffusion de documents scientifiques de niveau recherche, publiés ou non, émanant des établissements d'enseignement et de recherche français ou étrangers, des laboratoires publics ou privés. 


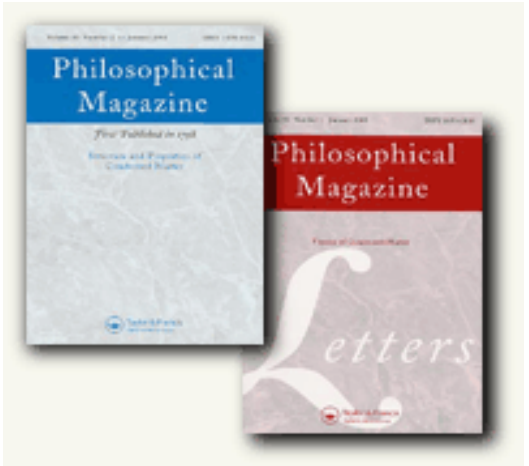

Ice internal friction: standard theoretical perspectives on friction codified, adapted for the unusual rheology of ice, and unified

\begin{tabular}{|r|l|}
\hline Journal: & Philosophical Magazine \& Philosophical Magazine Letters \\
\hline Manuscript ID: & TPHM-08-Oct-0381.R2 \\
\hline Journal Selection: & Philosophical Magazine \\
\hline Author: & $29-$ Subm-2009 \\
\hline & $\begin{array}{l}\text { Complete List of Authors: } \\
\text { Sammondted by the } \\
\text { Department } \\
\text { Feltham, Daniel; University College London, Earth Sciences } \\
\text { Department }\end{array}$ \\
\hline Keywords: & friction, ice, theoretical \\
\hline Keywords (user supplied): & friction, ice, theoretical \\
\hline & \multicolumn{2}{|l}{} \\
\hline
\end{tabular}

\section{S ScholarONE \\ Manuscript Central}


Philosophical Magazine,

Vol. 00, No. 00, DD Month 200x, 1-46

\title{
Ice internal friction: standard theoretical perspectives on friction codified, adapted for the unusual rheology of ice, and unified
}

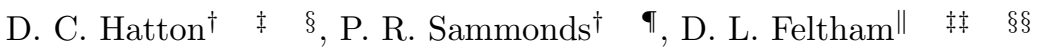 \\ (Received 00 Month 200x; in final form 00 Month 200x)
}

\begin{abstract}
Sea ice contains flaws including frictional contacts. We aim to describe quantitatively the mechanics of those contacts, providing local physics for geophysical models. With a focus on the internal friction of ice, we review standard micro-mechanical models of friction. The solid's deformation under normal load may be ductile or elastic. The shear failure of the contact may be by ductile flow, brittle fracture, or melting and hydrodynamic lubrication. Combinations of these give a total of six rheological models. When the material under study is ice, several of the rheological parameters in the standard models are not constant, but depend on the temperature of the bulk, on the normal stress under which samples are pressed together, or on the sliding velocity and acceleration. This has the effect of making the shear stress required for sliding dependent on sliding velocity, acceleration, and temperature. In some cases, it also perturbs the exponent in the normal-stress dependence of that shear stress away from the value that applies to most materials.

We unify the models by a principle of maximum displacement for normal deformation, and of minimum stress for shear failure, reducing the controversy over the mechanism of internal friction in ice to the choice of values of four parameters in a single model. The four parameters represent, for a typical asperity contact, the sliding distance required to expel melt-water, the sliding distance required to break contact, the normal strain in the asperity, and the thickness of any ductile shear zone.
\end{abstract}

\section{Introduction}

The internal friction of ice, i.e. the process whereby two samples of the same material, pressed together by an average normal stress $\sigma$, resist shearing of the contacting interface, with an average resisting shear stress $\tau$, is a particularly timely issue. In a previous paper, we presented a homogenization method, which will allow us to construct an ocean-scale model of sea-ice dynamics [1]. Its results will be derived from sub-grid-scale physical laws given as an input to the homogenization method. That creates a need to know the sub-grid-scale physics of floating ice sheets that contain various kinds of flaws, such as openwater leads, or normal-stress-created contacts between individual ice floes. The latter kind of flaws are the preserve of micro-mechanical internal friction models; they are also the preserve of laboratory ice-ice friction experiments, of which many have been presented in the literature, e.g. [2-16]. Sliding on networks of flaws of this kind contributes much of the strain in compressive deformation of ice [15], including sea ice in the field $[16,17]$. In the above, "average" means the spatial mean over an area of the two-dimensional facing surfaces large compared with the square of their roughness wavelength. The process is illustrated in figure 1 .

In this paper, we explore previously-published micro-mechanical models for predicting the shear stress $\tau$ required to induce sliding in internal friction. We take a particular interest in how these models might apply to the internal friction of ice. We propose to move forward from the position already established in the literature in three ways. Firstly, we will bring together the various models, with their widely differing micro-mechanical assumptions, in one place, permitting ready comparison between the results produced with different assumptions. Secondly, we will note several effects of the unusual rheology of ice, in which

\footnotetext{
'Rock and Ice Physics Laboratory Earth Sciences Department University College London Gower Street, London, UK. WC1E 6BT $\ddagger$ d.hatton@ucl.ac.uk

$\S$ Present address: Institute of Theoretical Geophysics, Cambridge University, Wilberforce Road, Cambridge, UK. CB3 0EZ

"p.sammonds@ucl.ac.uk

$\|$ Centre for Polar Observation and Modelling, Earth Sciences Department University College London Gower Street, London, UK. WC1E 6BT

¥† British Antarctic Survey, High Cross, Madingley Road, Cambridge, UK. CB3 0ET

$\S \S$ dlf@cpom.ucl.ac.uk
}

Philosophical Magazine 


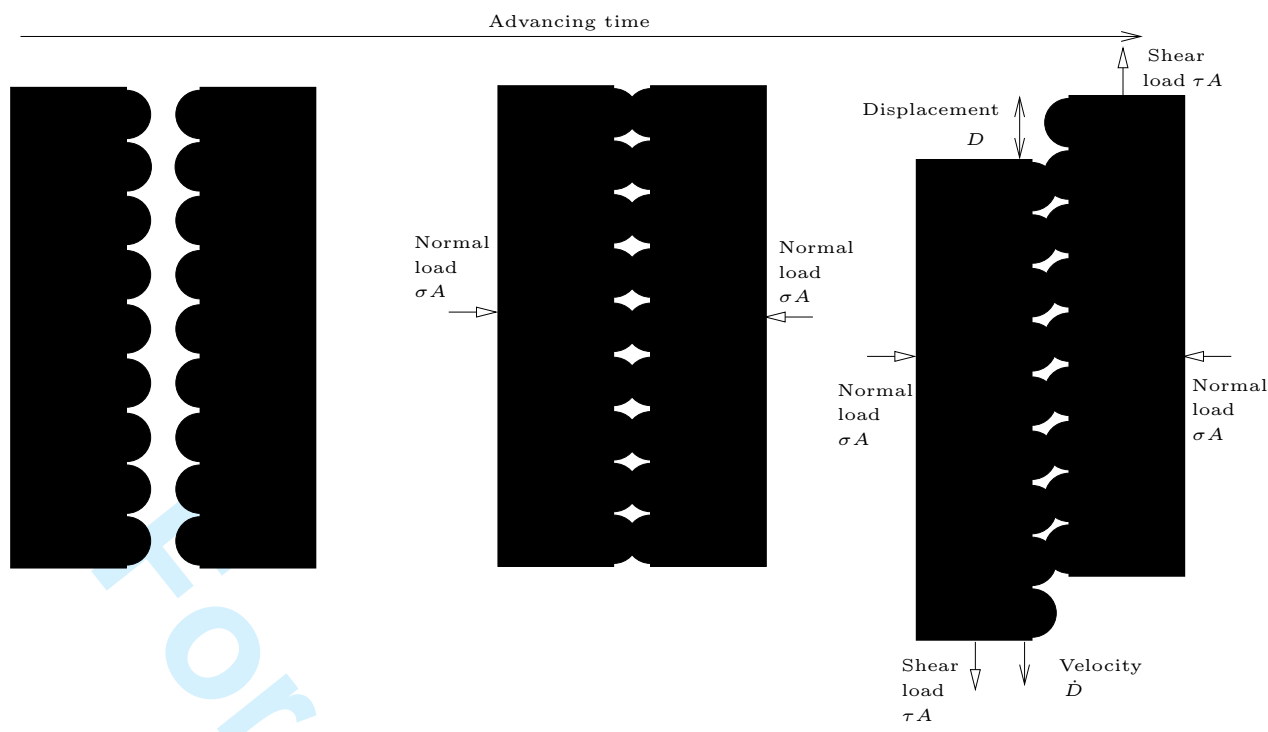

Figure 1. Schematic of sliding process involved in internal friction, with definitions of relevant quantities. $A$ is cross-sectional area of facing surfaces.

properties like Young's modulus and yield stress, included in standard internal friction models as constant parameters, depend on, e.g., strain rate and temperature. This introduces new independent variables and parameters into the laws for predicting $\tau$ generated by the models. Thirdly, we will propose unification of the models by a principle of maximum displacement for normal deformation, and of minimum stress for shear failure. Thus, at the end of this paper, we will have a formula, arising from our unified model, with just four adjustable parameters, for the local physics to insert into the homogenization method, where the ice contains normal-stress-created contact flaws. This means that the micro-mechanical and empirical approaches to friction are not mutually exclusive, but complementary. One could say that macroscopic laboratory friction experiments provide a way of discovering the values of the four adjustable parameters; equivalently, one could say that the four adjustable parameters provide a compact way of describing the results of a macroscopic laboratory friction experiment. The detailed understanding of micro-mechanical models that we will develop in this paper will be a necessary prerequisite for using empirical data in this way. Indeed, because four independent variables turn out to be relevant, the data are scattered over a five-dimensional variable space, and even generating meaningful plots of a full data set requires theoretical understanding of how to group or constrain variables to reduce the dimensionality of variable space.

Micro-mechanical models of friction (internal or otherwise), allowing for the fact that the facing surfaces are not perfectly flat, have analysed the process into two steps (e.g. [18]). Firstly, normal stress brings the facing surfaces into direct contact at a set of surface peaks, totalling a fraction $f$ of the facing-surface area. $f$ is determined by the size of $\sigma$, the rheology of the material under normal stress, and the topography of the surfaces. Secondly, this direct contact area exhibits the material's usual shear strength T, which is responsible for the interface's shear resistance

$$
\tau=f \mathrm{~T}
$$

Theoretical predictions for $f$ have been made for cases where the rheology of the material under normal stress is ductile $\left(f_{d u}\right)$ [18] or elastic $\left(f_{e l}\right)$, (e.g. [19]). The former case involves a parameter describing material properties: the yield stress $\mathrm{T}_{d u}$ of the material. The latter case also has parameters describing material properties: the Young's modulus $E$ and Poisson's ratio $\nu$ of the material, in addition to several parameters describing the surface topography of a particular sample [20], which we will discuss in detail in section 2.1.1,

The shear strength $\mathrm{T}$ may be the ductile yield stress $\mathrm{T}_{d u}[13,21]$, the brittle fracture stress in shear $\mathrm{T}_{b r}[13,22]$, or an effective shear strength $\mathrm{T}_{m l}$, representing a process whereby heat dissipated in frictional sliding melts part of the material surface, generating a fluid layer, which separates the peaks of the 


\section{ay 20, 2009

material surfaces, and undergoes two-dimensional Couette flow (cf. [23, p. 55]) between them [3]. This last possibility is only applicable to materials near their melting temperature, and was developed specifically for ice, although recently some related slip mechanisms have been discussed for deeply buried rocks [24,25]. For the former two failure modes, the shear strength itself is a parameter describing material properties, while in the latter case, it is constructed from thermodynamic properties of the material (thermal conductivity $\kappa$, specific heat capacity $c$, density $\rho_{s}$, melting temperature $\Theta_{m}$ in the relevant salinity conditions, assumed here to be $3.5 \mathrm{wt} \% \mathrm{NaCl}$, and specific latent heat of melting $L$ ), along with rheological properties of the liquid (dynamic viscosity $\eta$ and density $\rho_{l}$ ), and one parameter describing the surface topography of an individual sample (the typical distance $X$ that the surfaces have to slide relative to one another, between a fluid element being generated at the leading edge of an individual peak contact, and the same fluid element being ejected at the trailing edge of the peak contact) [3]. The shear strength in this case depends on the temperature $\Theta$ of the bulk solid, and on the sliding velocity $\dot{D}$.

Either of the two normal-rheology models (ductile or elastic deformation) can be combined with any of the three shear-rheology models (ductile, brittle, or melting failure), producing six friction models in all.

As the citations of the literature above suggest, all of these models have been thoroughly studied. However, to apply them quantitatively to ice, there is more work to do, because for ice, the materialproperty parameters are not constant. In particular, $\mathrm{T}_{d u}$ depends on the shear strain rate $\dot{\epsilon}_{s}$, and on the temperature $\Theta[26]$. Also, elastic deformation is composed of a mixture of prompt and delayed effects [27], which can be expressed as a Young's modulus that depends on ice grain size $d_{G}$, the time-scale $t_{C}$ over which the load is applied, and $\Theta[27,28]$. Further, brittle shear fracture strength depends on local normal stress $\Sigma$ [22]. In addition, melting temperature depends on $\Sigma$ [29-31]. Finally, Poisson's ratio depends on $\Theta$ [32]. The upper two sections of table 1 describevarious universal constantsand constant material properties of ice, and give their values.

In section 2, we sketch the standard derivations of $f$ and T. For $f$, we give more details in supplementary online material A, In section 3, we explore how strain rate $\dot{\epsilon}_{s}$ and contact time $t_{C}$ depend on sliding velocity $\dot{D}$ and acceleration $\ddot{D}$, and how local normal stress $\Sigma$ depends on average normal stress $\sigma$. Hence, we develop expressions for the dependencies of the material parameters on the independent variables $\Theta, \sigma, \dot{D}$, and $\ddot{D}$, and finally explore the overall dependence of the sliding-resistance shear stress $\tau$ on these independent variables. On the way, we find we need to introduce the surface-topographic parameters included in the lower section of table 1.

\section{Recapitulation of classical friction laws}

\subsection{Contact fraction}

2.1.1 Elastic deformation under normal load. The literature [20,41] contains methods for calculating the real contact area between pieces of material that deform elastically under normal load. We give the algebraic details and full derivations in supplementary online material A. In this section, we summarize the results. A key aspect of these is that the real contact area depends on the topography of the ice surfaces, so we will give five expressions for the real contact fraction, each based on a different type of surface topography. We will later decide which expression to use based on the observed topography of a real contact surface (section 4). Crucial quantities are the adjusted Young's modulus

$$
E^{\prime}=\frac{E}{2\left(1-\nu^{2}\right)}
$$

the number $P$ of asperities (hummocks) per unit area of surface; the typical radius of curvature $R_{C}$ of an asperity peak; and the fraction $\phi(z) \mathrm{d} z$ of the asperities whose peaks, when undeformed, are at heights between $z$ and $z+\mathrm{d} z$ above some arbitrary reference height. In the first three types of topography, where the normal load deforms only the asperities on the surface, not the firmament beneath them, the basis of 
Hatton et al.

\begin{tabular}{|c|c|c|c|}
\hline Symbol & Name & Value & Source \\
\hline$R$ & Molar gas constant & $8.314472 \mathrm{~J} /(\mathrm{mol} \mathrm{K})$ & {$[33]$} \\
\hline $\begin{array}{c}G \\
n \\
E_{a} \\
E_{P} \\
d_{0} \\
t_{0} \\
p \\
S_{1} \\
b \\
\Theta_{m 0} \\
\Theta_{m 1} \\
C_{C C 1} \\
C_{C C 2} \\
\nu_{0} \\
\Delta \nu \\
\kappa \\
c \\
\rho_{s} \\
\rho_{l} \\
\eta \\
L\end{array}$ & $\begin{array}{c}\text { Glen's law coefficient } \\
\text { Glen's law exponent } \\
\text { Activation energy } \\
\text { Prompt Young's modulus } \\
\text { Elastic grain size scale } \\
\text { Elastic relaxation time } \\
\text { Elastic relaxation exponent } \\
\text { Brittle shear fracture coefficient } \\
\text { Brittle shear fracture exponent } \\
\text { Zero-pressure } \Theta_{m}, \text { ice } I h \\
\text { Zero-pressure } \Theta_{m}, \text { ice } I I I \\
\text { Ice Ih Clausius-Clapeyron coefficient } \\
\text { Ice } I I I \text { Clausius-Clapeyron coefficient } \\
\text { Poisson's ratio at } \Theta_{m 0} 0 \\
\text { Temperature derivative of Poisson's ratio } \\
\text { Ice thermal conductivity } \\
\text { Ice specific heat capacity } \\
\text { Ice density } \\
\text { Liquid brine density } \\
\text { Water dynamic viscosity } \\
\text { Specific latent heat of melting }\end{array}$ & $\begin{array}{c}3.565 \times 10^{-12} /\left(\mathrm{Pa}^{n} \mathrm{~s}\right) \\
3 \\
65.7 \mathrm{~kJ} / \mathrm{mol} \\
9.3 \mathrm{GPa} \\
9 \mathrm{~mm} \\
199 \mathrm{ps} \\
0.34 \\
220 \mathrm{~Pa}^{1-b} \\
0.67 \\
271.5 \mathrm{~K} \\
251.5 \mathrm{~K} \\
84.3 \mathrm{nK} / \mathrm{Pa} \\
56.3 \mathrm{nK} / \mathrm{Pa} \\
0.339 \\
7.0 \times 10^{-5} / \mathrm{K} \\
2.3 \mathrm{~W} /(\mathrm{m} \mathrm{K}) \\
2.097 \mathrm{~kJ} /(\mathrm{kg} \mathrm{K}) \\
920 \mathrm{~kg} / \mathrm{m}^{3} \\
1.034 \mathrm{t} / \mathrm{m}^{3} \\
1.792 \mathrm{mPas} \\
333 \mathrm{~kJ} / \mathrm{kg}\end{array}$ & $\begin{array}{c}{[27,28]} \\
{[11,27,28]} \\
{[11,27,28]} \\
{[27]} \\
{[28]} \\
{[27]} \\
{[27,28]} \\
{[22]} \\
{[22]} \\
{[34]} \\
{[31]} \\
{[30]} \\
{[31]} \\
{[32]} \\
{[32]} \\
{[35]} \\
{[36]} \\
{[37]} \\
{[38]} \\
{[39]} \\
{[40]}\end{array}$ \\
\hline $\begin{array}{c}P \\
Q \\
R_{C} \\
R_{D} \\
R_{E} \\
X \\
Y \\
Z \\
\epsilon_{\star}\end{array}$ & $\begin{array}{c}\text { Areal density of asperities } \\
\text { Areal density of super-asperities } \\
\text { Typical asperity radius of curvature } \\
\text { Super-asperity radius of curvature } \\
\text { Super-super-asperity radius of curvature } \\
\text { Sliding distance for water expulsion } \\
\text { Sliding distance to break contact } \\
\text { Shearing layer thickness } \\
\text { Typical contact strain }\end{array}$ & $\begin{array}{c}5.53 \times 10^{6} / \mathrm{m}^{2} \\
1.34 \times 10^{4} / \mathrm{m}^{2} ? \\
160.4 \mu \mathrm{m} \\
4.87 \mathrm{~mm} \\
4.875 \mathrm{~mm} \\
\text { Adjustable } \\
\text { Adjustable } \\
\text { Adjustable } \\
\text { Adjustable }\end{array}$ & $\begin{array}{c}\text { Section } 4 \\
\text { Section } 4 \\
\text { Section } 4 \\
\text { Section } 4 \\
\text { Section } 4 \\
\text { Mechanical experiments } \\
\text { Mechanical experiments } \\
\text { Mechanical experiments } \\
\text { Mechanical experiments }\end{array}$ \\
\hline
\end{tabular}

the analysis is the integral formulae

$$
\sigma=\frac{4 P E^{\prime} R_{C}^{1 / 2}}{3} \int_{z=d}^{\infty}(z-d)^{3 / 2} \phi(z) \mathrm{d} z
$$

and

$$
f_{e l}=\pi P R_{C} \int_{d}^{\infty}(z-d) \phi(z) \mathrm{d} z
$$

[20]. The first of these implicitly determines the height $d$, to which peaks originally higher than $d$ must be depressed, to bear normal stress $\sigma$. The second then describes how depression of the peaks increases the contact area, both by bringing more asperities into contact, and by increasing the contact area contributed by each contacting asperity. 


\section{Page 5 of 24

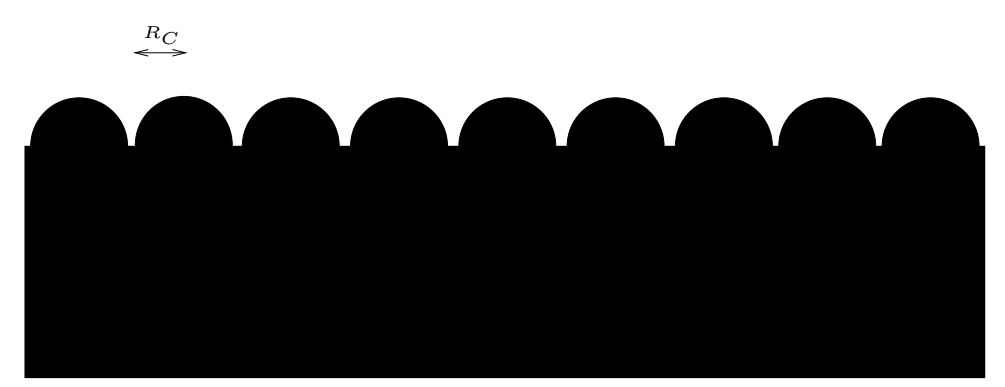

Figure 2. Schematic of surface topography with delta-function distribution of peak heights

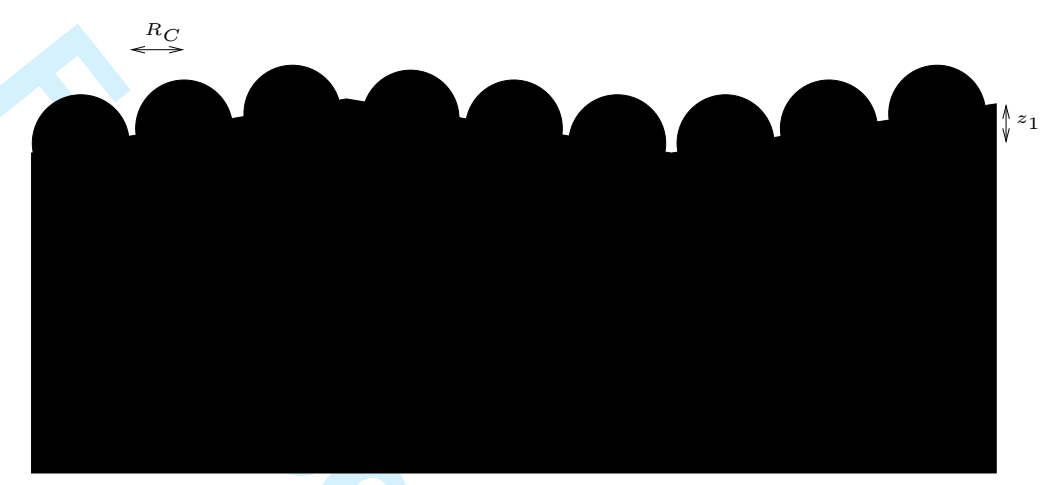

Figure 3. Schematic of surface topography with top-hat distribution of peak heights

A topography with a delta-function distribution of peak heights is illustrated in figure2. This topography has a peak-height distribution

$$
\phi(z)=\delta\left(z-z_{0}\right)
$$

$z_{0}$ is a parameter to be determined by observation of a real contact surface (section 44). For this peak height distribution, the real contact fraction is

$$
f_{e l}=\frac{\pi P^{1 / 3} R_{C}^{2 / 3}}{4^{2 / 3} E^{\prime 2 / 3}} \sigma^{2 / 3} .
$$

A topography with a top-hat distribution of peak heights is illustrated in figure 3. This topography has a peak height distribution

$$
\phi(z)=\frac{1}{z_{1}}
$$

$\left(z_{0} \leq z<z_{0}+z_{1}\right)$

$$
\phi(z)=0
$$

(all other $z$ ). $z_{0}$ and $z_{1}$ are parameters to be determined by observation of a real contact surface (section 4). For this peak height distribution, the real contact fraction is

$$
f_{e l}=\frac{15^{4 / 5} \pi P^{1 / 5} R_{C}^{3 / 5}}{2 \times 8^{4 / 5} E^{4 / 5} z_{1}^{1 / 5}} \sigma^{4 / 5} .
$$

An exponential distribution of peak heights is illustrated in figure 4. This topography has a peak height 


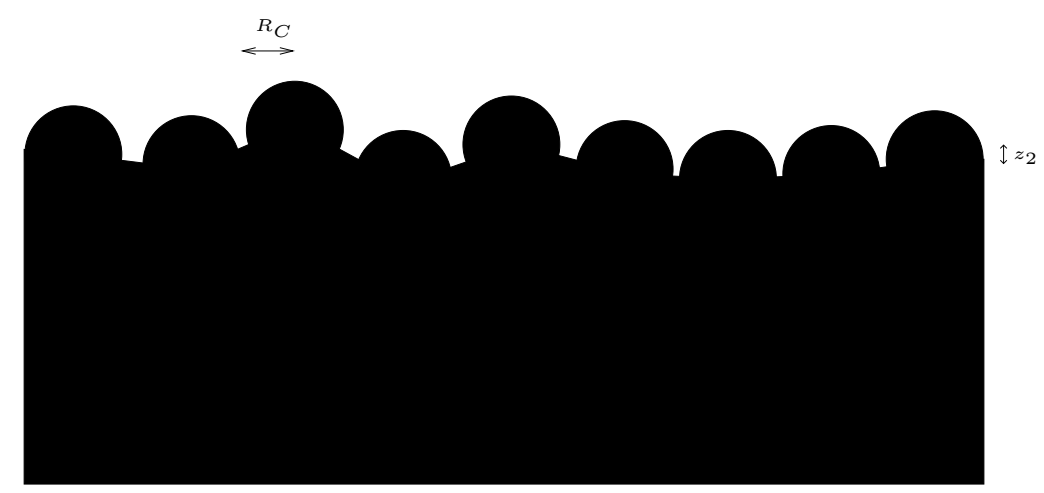

Figure 4. Schematic of surface topography with exponential distribution of peak heights

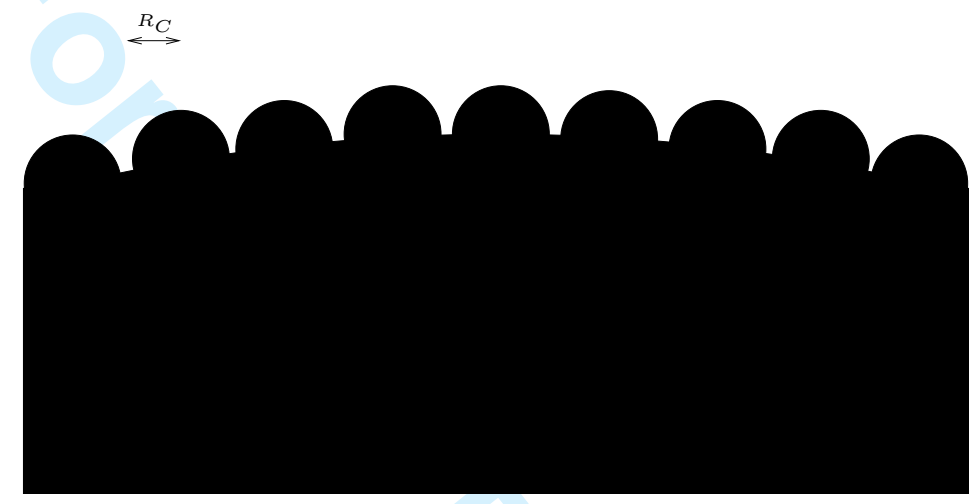

Figure 5. Schematic of one-step fractal surface topography.

distribution

$$
\phi(z)=\frac{1}{z_{2}} \exp \left(-\frac{z-z_{0}}{z_{2}}\right)
$$

$\left(z \geq z_{0}\right)$

$$
\phi(z)=0
$$

$\left(z<z_{0}\right) . z_{0}$ and $z_{2}$ are parameters to be determined by observation of a real contact surface (section 4). For this peak height distribution, the real contact fraction is

$$
f_{e l}=\frac{\pi^{1 / 2} R_{C}^{1 / 2}}{E^{\prime} z_{2}^{1 / 2}} \sigma .
$$

A one-step fractal topography is illustrated in figure 5. This topography has a peak height distribution

$$
\phi(z)=\frac{2\left(z-z_{0}\right)}{R_{D}^{2}}
$$

$\left(z_{0} \leq z<z_{0}+R_{D}\right)$

$$
\phi(z)=0
$$

(all other $z$ ), a histogram of which is shown in figure 6, $z_{0}$ and $R_{D}$ are parameters to be determined by 


\section{Page 7 of 24}

1

2

3

4

5

6

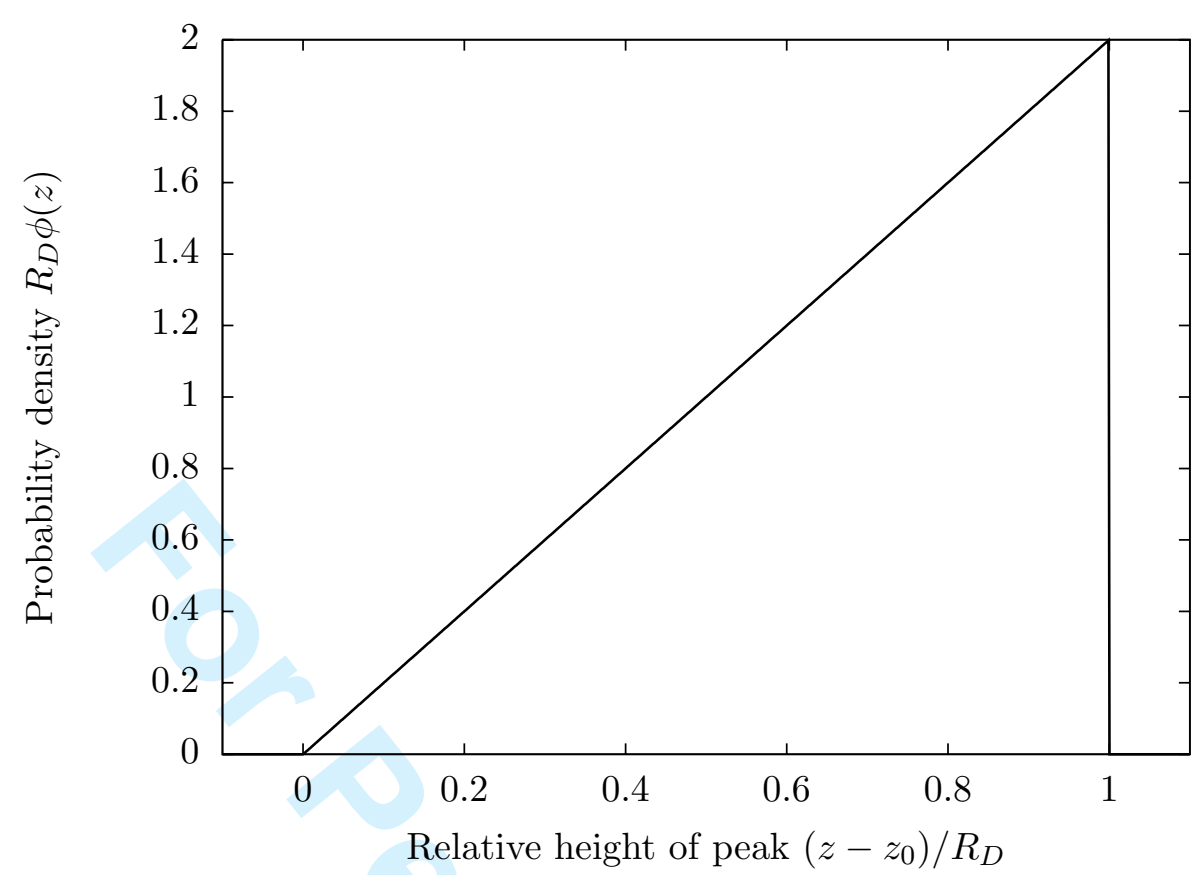

Figure 6. Histogram of one-step fractal peak height distribution

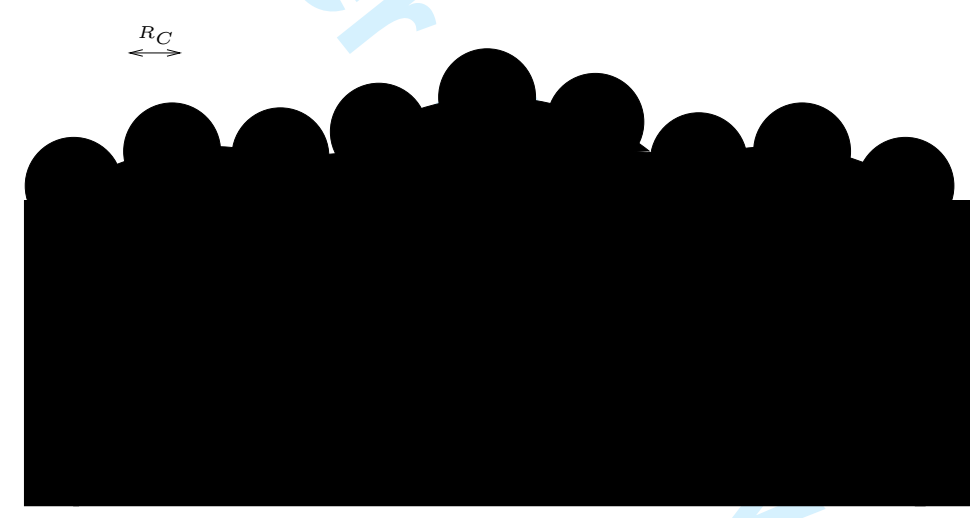

Figure 7. Schematic of two-step fractal surface topography.

observation of a real contact surface (section 4). For this peak height distribution, the real contact fraction is

$$
f_{e l}=\frac{3^{5 / 3} \pi^{11 / 9} P^{1 / 3} R_{C}^{2 / 3}}{4^{20 / 9} E^{\prime 8 / 9}} \sigma^{8 / 9}
$$

A two-step fractal topography is illustrated in figure 7. This topography has a peak height distribution

$$
\begin{gathered}
\phi(z)=\frac{2\left(z-z_{0}\right)^{3}}{3 R_{D}^{2} R_{E}^{2}} \\
\left(z_{0} \leq z<z_{0}+R_{D}\right), \quad \\
\phi(z)=\frac{2\left(z-z_{0}\right)}{R_{E}^{2}}-\frac{4 R_{D}}{3 R_{E}^{2}}
\end{gathered}
$$




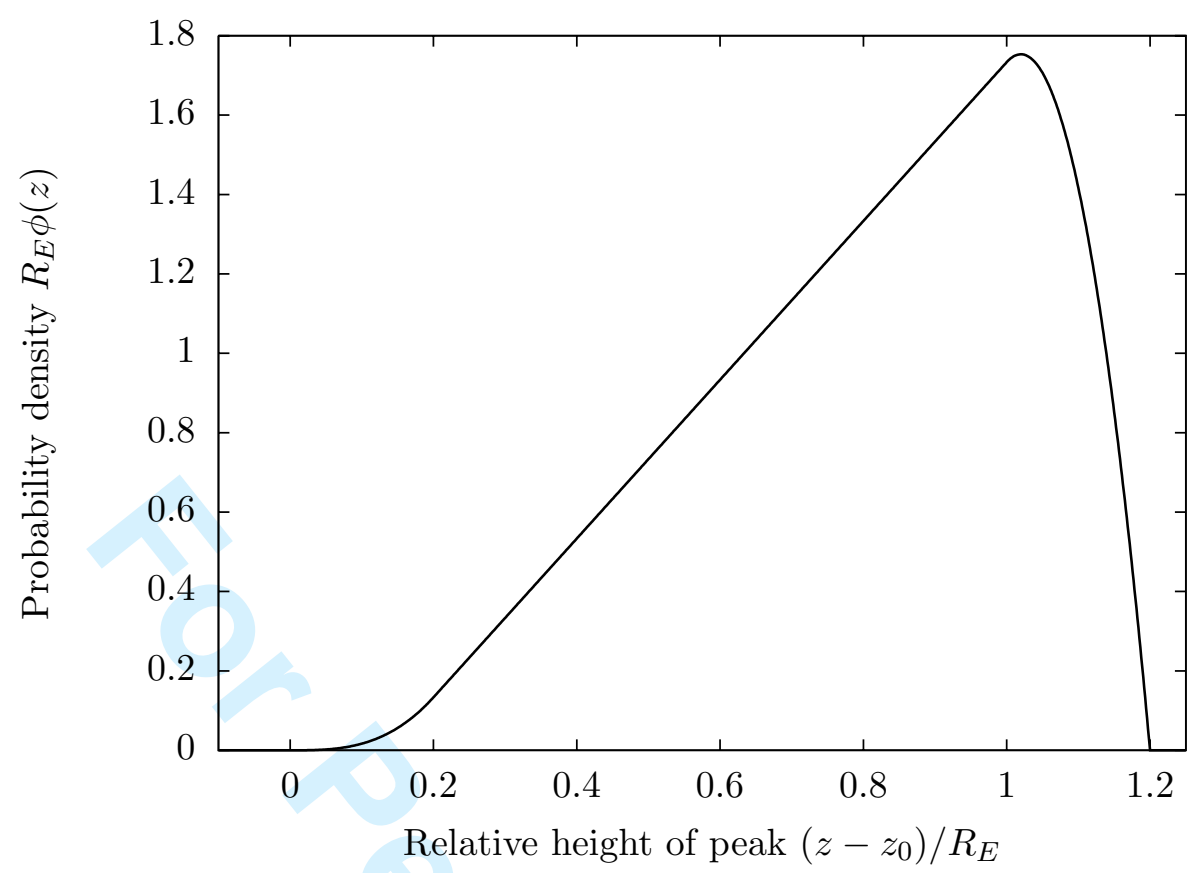

Figure 8. Histogram of two-step fractal peak height distribution, with $R_{D}=R_{E} / 5$

$$
\begin{gathered}
\left(z_{0}+R_{D} \leq z<z_{0}+R_{E}\right) \\
\phi(z)=\frac{2\left(z-z_{0}\right)}{R_{E}^{2}}-\frac{4 R_{D}}{3 R_{E}^{2}}-\frac{2\left(z-z_{0}\right)^{3}}{3 R_{D}^{2} R_{E}^{2}}+\frac{2\left(z-z_{0}\right)}{R_{D}^{2}}-\frac{4 R_{E}}{3 R_{D}^{2}} \\
\left(z_{0}+R_{E} \leq z<z_{0}+R_{E}+R_{D}\right), \\
\phi(z)=0
\end{gathered}
$$

(all other $z$ ), a histogram of which is shown in figure 8, $z_{0}, R_{D}$, and $R_{E}$ are parameters to be determined by observation of a real contact surface (section 4 ). For this peak height distribution, the real contact fraction is

$$
f_{e l}=\frac{3^{41 / 9} \pi^{35 / 27} P^{1 / 3} R_{C}^{2 / 3}}{2^{148 / 27} \times 13 E^{\prime 26 / 27}} \sigma^{26 / 27} .
$$

2.1.2 Ductile deformation under normal load. If, on the other hand, the material behaves in a ductile fashion under normal load, the asperities will deform, increasing the contact area and reducing the local stress $\Sigma=\sigma / f$ at the asperity tips until it reaches the compressive yield stress $S[42,43]$, which is:

$$
S=\left(\frac{\dot{\epsilon}_{n}}{G}\right)^{1 / n} \exp \left(\frac{E_{a}}{n R \Theta}\right)
$$

$[21,26]$, where $\dot{\epsilon}_{n}$ is the normal strain rate. This means

$$
f_{d u}=\left(\frac{G}{\dot{\epsilon}_{n}}\right)^{1 / n} \exp \left(-\frac{E_{a}}{n R \Theta}\right) \sigma .
$$




\subsection{Shear strength}

2.2.1 Ductile shear failure. The ductile shear strength has been determined empirically to be

$$
\mathrm{T}_{d u}=\frac{1}{2}\left(\frac{\dot{\epsilon}_{s}}{G}\right)^{1 / n} \exp \left(\frac{E_{a}}{n R \Theta}\right)
$$

$[26]$.

2.2.2 Brittle shear failure. The brittle shear strength has been determined empirically to be

$$
\mathrm{T}_{b r}=S_{1} \Sigma^{b}
$$

[22], where $b$ is the brittle shear fracture exponent (table 11).

2.2.3 Melting-lubrication shear failure. The effective shear strength in the melting-lubrication case results from the shear stress involved in two-dimensional Couette flow of a lubricating water layer between asperities of the two facing surfaces [3]. The thickness of the layer is determined by competition between water creation, by the part of the frictional heat that is not conducted away into the bulk of the ice, and water loss, as water is left behind by the moving asperities. The shear strength takes the value

$$
\mathrm{T}_{m l}=\frac{\operatorname{sgn}(\dot{D})}{\pi^{1 / 4} X^{1 / 2}}\left(\frac{\left(\kappa c \rho_{s}\right)^{1 / 2}\left(\Theta_{m}-\Theta\right)}{|\dot{D}|^{1 / 2}}+\left(\frac{\kappa c \rho_{s}\left(\Theta_{m}-\Theta\right)^{2}}{|\dot{D}|}+2 \eta L \rho_{l}|\dot{D}|\right)^{1 / 2}\right)
$$

[3]. As mentioned above, $X$ is the typical distance the material has to slide between melt-water being generated somewhere within an individual asperity contact, and the same melt-water being lost from the trailing edge of the individual asperity contact. $X$ is a topographic property of a particular sample; its involvement in this model, but not its value, is established in the literature [3]. Therefore, we will treat $X$ as an adjustable parameter, for eventual fitting to shear stress measurements in sliding. However, $X$ cannot be greater than the asperity radius of curvature, yet must be a significant fraction of the asperity radius of curvature in order to expel the fluid. Hence, in analysing mechanical experiments, we will represent $X$ by the dimensionless ratio $\hat{X}=X / R_{C}$, and restrict the adjustability of $\hat{X}$ to values between $10^{-2}$ and 1 .

\section{The oddities of ice}

Ice is "odd" (although not unique) in its rheology in four ways. Firstly, its ductile yield stress is dependent on strain rate. Secondly, its brittle fracture strength in shear is dependent on normal stress. Thirdly, its melting temperature decreases with increasing pressure. Fourthly, the elastic strain at a given stress (and therefore the adjusted Young's modulus) depends on how long the stress has been applied, and (directly and through Poisson's ratio) on the temperature. We did not discover these oddities; they are all established in the literature. However, we believe we are the first to take account of them in a friction model. In the following, we discuss how we will account for these dependences in a frictional context.

\subsection{Strain rate dependence of yield stress}

In the formulae for contact fraction under ductile normal deformation, and for shear strength under ductile shear failure (equations 23, 21) there appears an explicit strain rate $\dot{\epsilon}_{n}$ or $\dot{\epsilon}_{s}$. However, the literature from which these equations were taken does not include a method for obtaining these strain rates from variables more typically quoted in friction studies; we will now propose such a method. In the context of sliding, 
strain rates must bear some relationship to sliding velocity. For the shear strain rate, we define a shearing layer thickness $Z$, which is a topographic property of a particular sample, and will need to be treated as an adjustable parameter, for eventual fitting to shear stress measurements in sliding. Then

$$
\dot{\epsilon}_{s}=\frac{\dot{D}}{Z}
$$

$Z$ cannot be greater than the asperity radius of curvature, because, as long as $f \ll 1$, the asperity contacts will contain a region of space (bounded in the $z$ direction) where the cross-sectional area is much smaller than that of the bulk ice, and the localized shear stress is therefore much larger than in the bulk ice, localizing the deformation region within the asperities. In all the circumstances we will examine in section 7. $f<0.0014$. In addition, we will not seek to handle cases where $Z$ is smaller than $\sim 1 \mu$ m, because ductile deformation on such small scales obeys different laws $[44,45]$. Hence, for analysing mechanical experiments, we will represent $Z$ by the dimensionless ratio $\hat{Z}=Z / R_{C}$, and restrict the adjustability of $\hat{Z}$ to values between $1 \mu \mathrm{m} / R_{C}$ and 1 .

For the normal strain rate, on the other hand, we need to consider the history of an individual asperity contact. If an individual asperity contact has typically existed for time $t_{C}$, and has typically been produced by the introduction of a normal strain $\epsilon_{\star}$, then

$$
\dot{\epsilon}_{n}=\frac{\epsilon_{\star}}{t_{C}}
$$

We consider $\epsilon_{\star}$ to be a topographic property of a particular sample, and treat it as an adjustable parameter for eventual fitting to shear stress measurements. When we do this, we will assume that only asperities with enough contact for ordinary macroscopic plasticity theory to apply, i.e. at least $1 \mu \mathrm{m}^{2}$, are important, and that asperities are not completely crushed, restricting the adjustability to $1 \mu \mathrm{m} / R_{C} \leq \epsilon_{\star}<1$.

$t_{C}$ may depend, in general, not only on instantaneous sliding velocity, but also on velocity history. For the sake of simplicity, we approximate the velocity history by a linear function of time. Then the time a typical asperity contact has existed is the smallest non-negative value allowed by the two \pm signs of

$$
t_{C}=\frac{\dot{D} \pm{ }^{(1)} \sqrt{\dot{D}^{2} \pm^{(2)} 2 Y \ddot{D}}}{\ddot{D}}
$$

where $Y$ is an adjustable parameter representing the typical sliding distance between an asperity contact being formed and being broken. This cannot be greater than the asperity radius of curvature, yet must be a significant fraction of the asperity radius of curvature in order to break the contact. Therefore, when we eventually fit models to mechanical data, we will express it as the dimensionless ratio $\hat{Y}=Y / R_{C}$, and restrict the adjustability of this ratio to values between $10^{-2}$ and 1 .

Thus, the effect of the strain rate dependence of yield stress is to introduce velocity dependences into the ductile contact fraction and ductile shear stress. The famous Coulomb's law has $\tau \propto \sigma$, and $\tau$ independent of velocity. Where both normal and shear deformation are ductile, and the material is ice, Coulomb's law represents the low-acceleration limit $|2 Y \ddot{D}| \ll \dot{D}^{2}$, where the velocity dependences in $f$ and T cancel.

\subsection{Pressure dependence of brittle strength}

In Rist and Murrell's [22] expression for brittle shear strength (equation 24), there appears an explicit, local normal stress at the asperity contacts $\Sigma$. We propose that, to bear the appropriate load, it must be given by

$$
\Sigma=\frac{\sigma}{f}
$$




\section{May $20,2009 \quad 12: 4$}

Page 11 of 24

This means that, if the failure of the contact is brittle and the real contact fraction

$$
f \propto \sigma^{e_{0}}
$$

as is the case in equations 6, 9, 12, 15, 20, and 22, then

$$
\Sigma \propto \sigma^{1-e_{0}}
$$

According to equation 24, this means a shear strength

$$
\mathrm{T}_{b r} \propto \sigma^{\left(1-e_{0}\right) b} .
$$

Then equation 1 gives a sliding shear stress

$$
\tau \propto \sigma^{b+(1-b) e_{0}}
$$

This tends to bring the sliding shear stress closer to direct proportionality to normal stress. For example, with elastic normal deformation and a delta-function distribution of peak heights (equation [6), brittle failure will alter the exponent from $e_{0}=2 / 3$ to $b+(1-b) e_{0} \approx 8 / 9 . b+(1-b) e_{0}$ is always significantly larger than $b$ - so finding an empirical exponent between frictional shear stress and normal stress close to $b$ (cf. [9]) would not necessarily be characteristic of brittle shear failure.

\subsection{Pressure dependence of melting temperature}

The melting temperature involved in equation 25 is the higher of

$$
\Theta_{m}=\Theta_{m 0}-C_{C C 1} \Sigma
$$

(representing the low-pressure ice Ih phase) and

$$
\Theta_{m}=\Theta_{m 1}+C_{C C 2} \Sigma
$$

(representing the high-pressure ice I3 phase) [30,31]. As in our proposal of section [3.2, the local pressure implicated in the melting-temperature expressions (equations 34, 35) is

$$
\Sigma=\frac{\sigma}{f} .
$$

If shear failure is by melting and hydrodynamic lubrication, this means that while, at small normal stresses $\left(\sigma \ll\left|f\left(\Theta-\Theta_{m i}\right) / C_{C C i}\right|\right)$, where $\mathrm{T}$ is independent of $\sigma$, the exponent in the normal stress dependence of the sliding shear stress will be the same $\left(e_{0}\right)$ as that in the normal stress dependence of the real contact fraction, at large normal stresses $\left(\sigma \gg\left|f\left(\Theta-\Theta_{m i}\right) / C_{C C i}\right|\right)$, where $\mathrm{T} \propto \sigma / f$, sliding shear stress will be directly proportional to normal stress, regardless of the rheology under normal load (section 2.1).

\subsection{Time and temperature dependence of adjusted Young's modulus}

The Young's modulus of ice is given by

$$
E=\frac{E_{P}}{1+\left(d_{0} / d_{G}\right)\left(1-\exp \left(-\left(\exp \left(-E_{a} /(R \Theta)\right) t_{C} / t_{0}\right)^{p}\right)\right)}
$$

$[27,28]$. As suggested in this equation, we propose to use the same time $t_{C}$ for the time of stress application in this formula as for the contact time in equation 27. In addition, the Poisson's ratio, used in the 
adjustment of Young's modulus in equation 2, depends on temperature:

$$
\nu=\nu_{0}+\Delta \nu\left(\Theta_{m 0}-\Theta\right)
$$

$[32]$.

\section{What is the surface topography of real ice like?}

Given that, in models with elastic deformation under the normal load, the surface topography of the ice is crucial in determining the friction law, it is important to understand the surface topography of real ice. Previously, we undertook a programme of sliding experiments on floating ice sheets (cf. [14]). The ice used in these experiments was grown to a thickness of $\sim 170 \mathrm{~mm}$, over a period of $\sim 1$ week, in the Arctic Environmental Test Basin at Hamburgische Schiffbau Versuchsanstalt, a tank of salt water $30 \mathrm{~m}$ long, $6 \mathrm{~m}$ wide, and $1.2 \mathrm{~m}$ deep, by refrigerating the air above. Photographs of thin sections of this ice between crossed polarizers are shown in figure 9, and in a colour version in figure B1 of supplementary online material B. They confirm that the ice has a columnar (i.e. sea-ice-like) fabric.

At the end of the programme of experiments, we used a commercial rubber solution (Microset 101RF, cf. [46]) to take a cast of a small area of one of the facing surfaces, which had undergone repeated back-and-forth sliding during the experiments. The surface profile of the ice, as measured from the cast using a commercial optical profilometer (cf. [47]), is shown in figure 10, The raw data from which this graph is constructed are tabulated in supplementary online material C. As discussed in more detail in supplementary online material D, we believe that this surface topography is controlled primarily by the sliding process, not by the ice growth, nor by the cutting method initially used to produce the faults; certainly the topography of a surface that has undergone repeated sliding (figure D1 in supplementary online material (D) is very different from that of a freshly-cut surface (figure D2 in supplementary online material (D), while the topographies of surfaces that have undergone repeated sliding from ice of different chemistries (figure D1 in supplementary online material DD and figure [10) are rather similar. We believe this provides evidence that geophysical floating ice sheets, which have undergone a similar repeated-sliding process, will have similar topography, allowing our results to be generalized from our particular ice sample to ice rheology in the field. We attribute this to the sliding process producing material akin to "fault gouge" in rock mechanics (cf. [48]), which then refreezes to the bulk ice, producing the surface topography in figure 10.

The relevant properties of this profile are the heights, radii of curvature, and areal density of its peaks. By "peaks", we mean local maxima of height. Two points are particularly noteworthy here. Firstly, the figure is in the orientation of the ice, not of the cast, so that asperities are represented by bright spots, not by dark spots. Secondly, the height $z$ of the tip of an asperity is measured from an arbitrary reference plane pertaining to the whole surface, not from the base of that particular asperity - so that a peak being high (large $z$ ) yet small (small radius of curvature) does not necessarily mean that the aspect ratio of the asperity associated with it is far from unity: it may stand on a plateau (or a super-asperity, cf. supplementary online material (A); in mountaineering terms, $z$ is "elevation", not "prominence".

In supplementary online material E, we describe a method of finding the peaks in the profile, and obtaining from them the areal density of peaks, which turns out to be $P=5.53 / \mathrm{mm}^{2}$, and the typical radius of curvature of a peak, which turns out to be $R_{C}=160.4 \mu \mathrm{m}$ (this makes the lower limit on $\epsilon_{\star}$, as discussed above, $\left.1 \mu \mathrm{m} / R_{C}=6.2 \times 10^{-3}\right)$. A histogram of the peak heights found is shown in figure 11. This list of peak heights can be used to infer which of the topographic models is most appropriate, and what the parameters of that model are. Each model directly specifies a likelihood value $\phi(z)$ for each peak, that is, the relative probability that a peak of that height occurs, given particular values of the model's parameters. One can obtain an overall likelihood (goodness of fit) for these parameter values by taking the product, over all the peaks, of $\phi(z)$. It is then reasonably straightforward to compare the models by their marginal likelihood. The marginal likelihood is the mean likelihood, over all parameter values, weighted by the a priori plausibility of the parameter values (prior probability distribution). This is equivalent to the product of a factor representing the best fit to the data the model can achieve (the likelihood maximized 


\section{Page 13 of $24 \quad$ Philosophical Magazine \& Philosophical Magazine Letters}

1

2

3

4

5

6

7

8

9
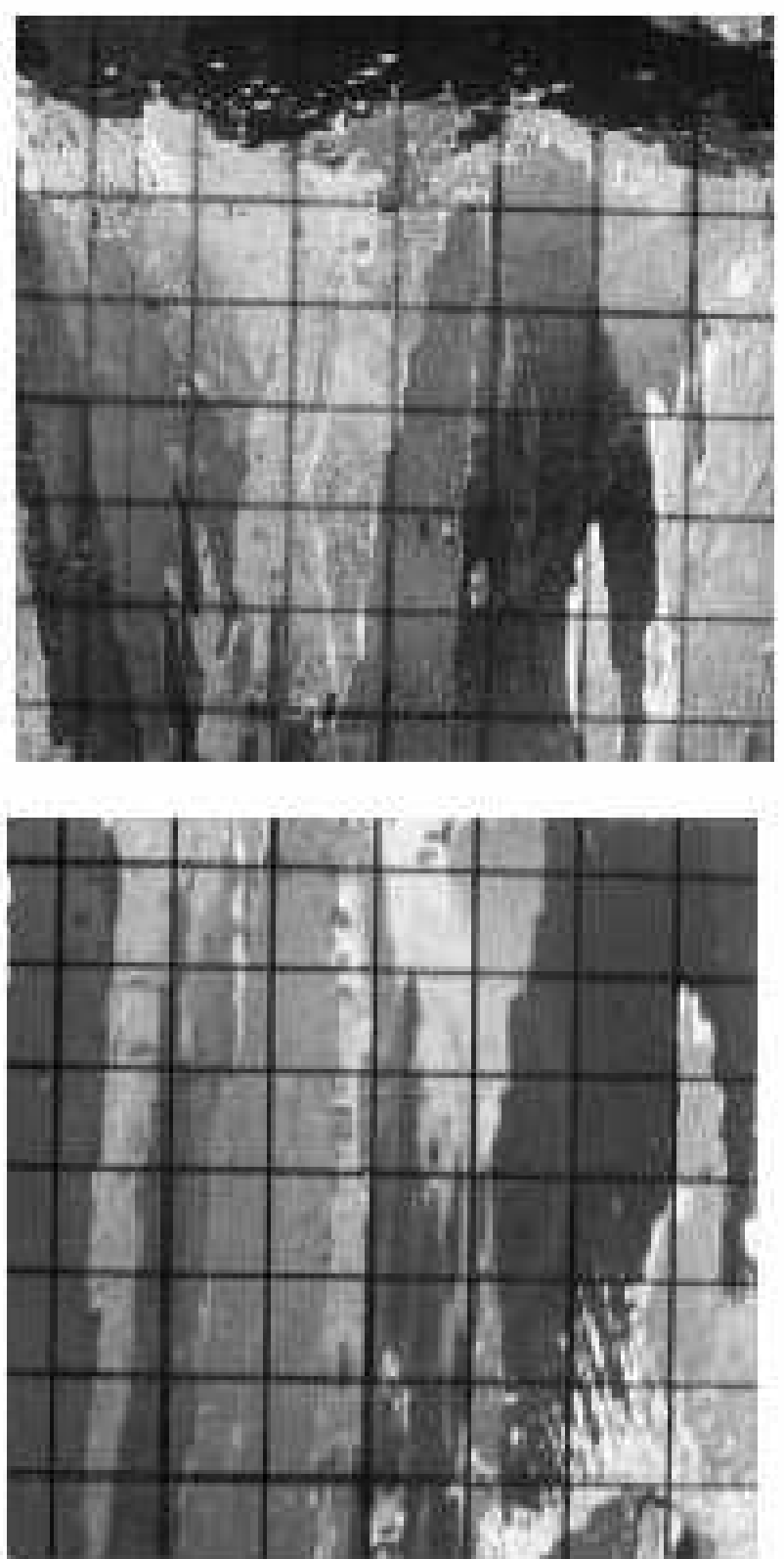

\section{Vertical sections}
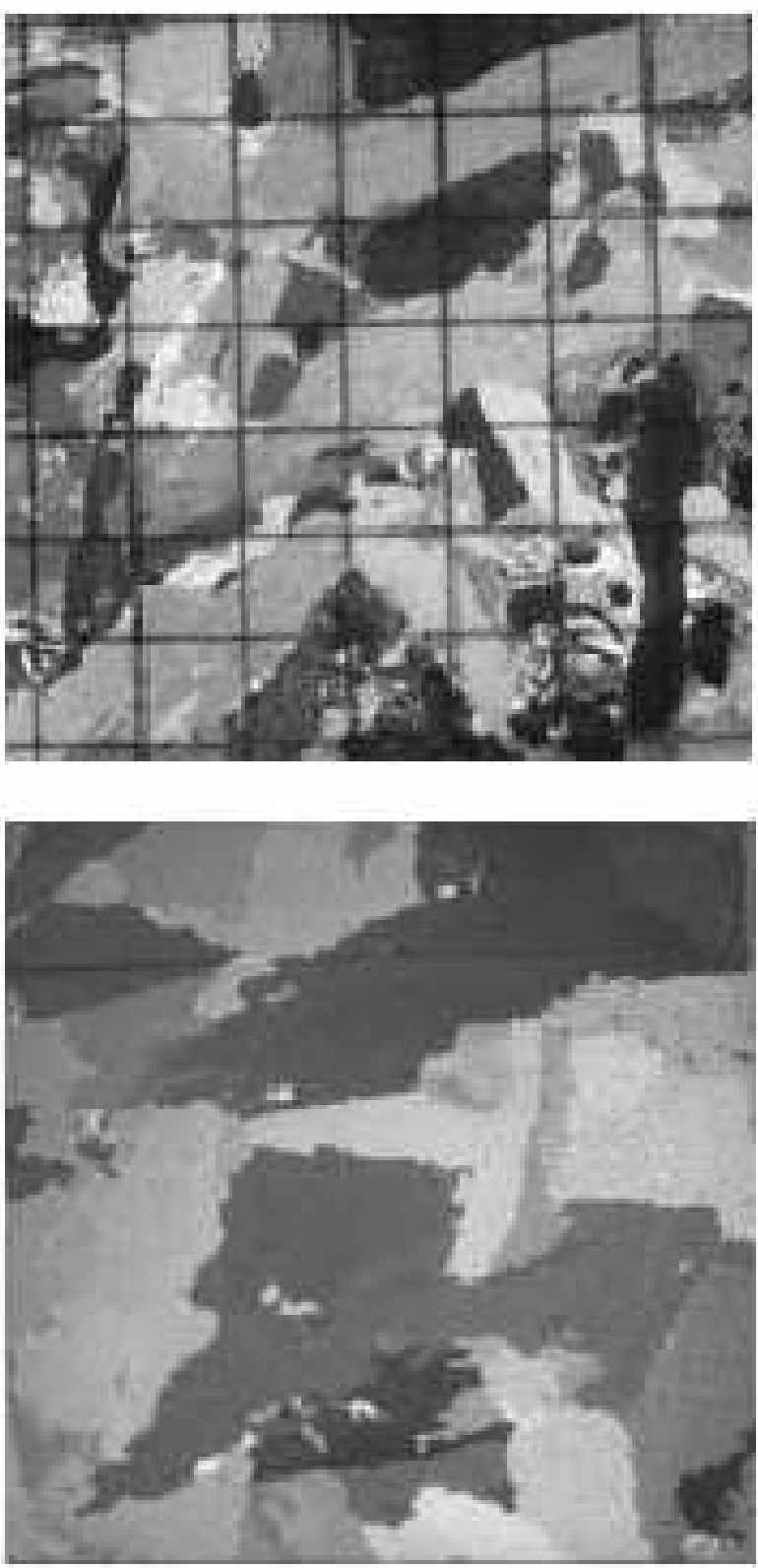

\section{Horizontal sections}

Figure 9. Photographs of thin sections, between crossed polarizers, of ice used in experiments; superimposed grid squares are $10 \mathrm{~mm} \times 10 \mathrm{~mm}$. Top left: vertical section, parallel to and $250 \mathrm{~mm}$ from sliding surface, topmost $90 \mathrm{~mm}$ of ice; bottom left: vertical section, parallel to and $250 \mathrm{~mm}$ from sliding surface, $90-180 \mathrm{~mm}$ below ice surface; top right: horizontal section, $100-250 \mathrm{~mm}$ from sliding surface, $15 \mathrm{~mm}$ below top of ice; bottom right: horizontal section, 100-250 mm from sliding surface, $90 \mathrm{~mm}$ below top of ice.

with respect to the parameters), and an "Occam factor" that penalizes a model for achieving its goodness of fit by fine-tuning parameters (cf. [49]). Comparing marginal likelihoods can be seen as the Bayesian equivalent of a significance test (cf. [50]). We used Monte-Carlo integration methods (cf. [51]) to take the necessary means of the likelihoods over parameter values. The computer code we used for this can be found in supplementary online material G. As shown in table 2, the two-step fractal model had overwhelmingly the largest marginal likelihood. Some explanation is in order of the strange unit $1 / \mathrm{mm}^{3593}$; a likelihood 


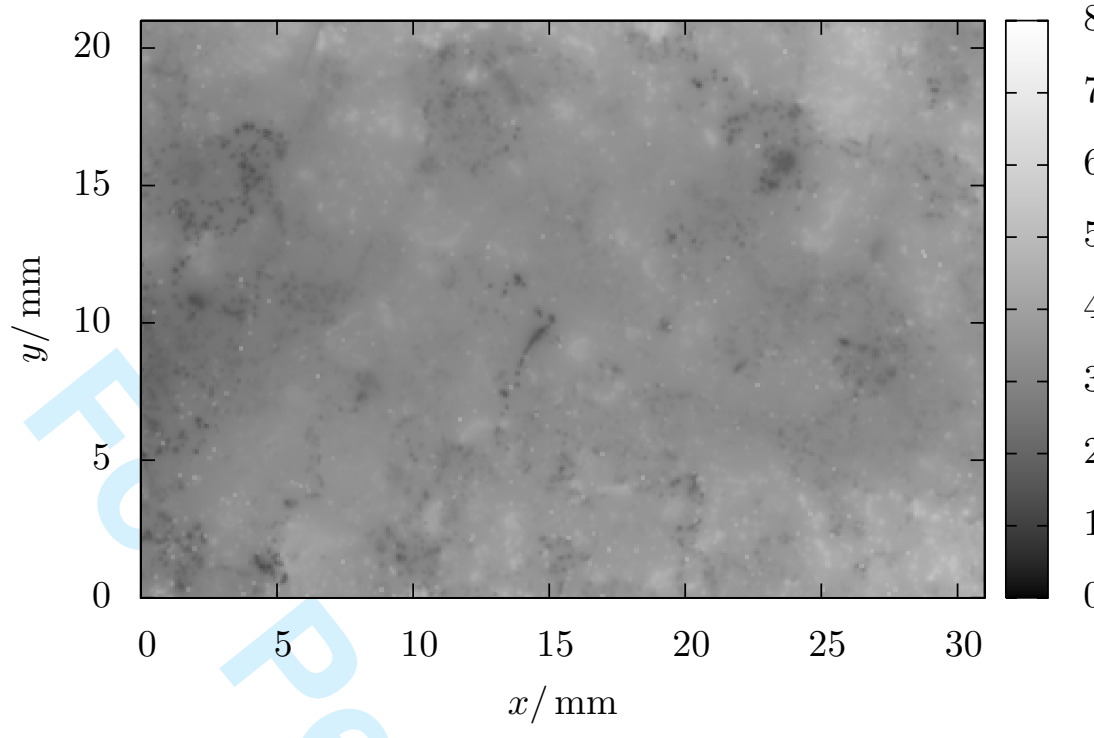

Figure 10. Topographic profile of an ice surface, which had undergone repeated back-and-forth sliding.

\begin{tabular}{|c|c|c|c|}
\hline Model & Marginal likelihood & Best fit parameters & Best fit likelihood \\
& $\exp (-5896.6) / \mathrm{mm}^{3593}$ & $z_{0}=-2.12 \mathrm{~mm}, R_{D}=4.87 \mathrm{~mm}$, & $\exp (-5894.29) / \mathrm{mm}^{3593}$ \\
\hline Two-step fractal & $R_{E}=4.875 \mathrm{~mm}$ & $\exp (-6002.1) / \mathrm{mm}^{3593}$ \\
Exponential & $\exp (-6018.5) / \mathrm{mm}^{3593}$ & $z_{0}=1.849 \mathrm{~mm}, z_{2}=2 \mathrm{~mm}$ & $\exp (-6305.8) / \mathrm{mm}^{3593}$ \\
Top-hat & $\exp (-6326.1) / \mathrm{mm}^{3593}$ & $z_{0}=1.8485 \mathrm{~mm}, z_{1}=5.8 \mathrm{~mm}$ & $\exp (-7358.7) / \mathrm{mm}^{3593}$ \\
One-step fractal & $\exp (-7373.8) / \mathrm{mm}^{3593}$ & $z_{0}=0 \mathrm{~mm}, R_{D}=8 \mathrm{~mm}$ & $\exp (-7162278313.0) / \mathrm{mm}^{3593}$ \\
Delta-function & $\exp (-7162278327.6) / \mathrm{mm}^{3593}$ & $z_{0}=3.80376 \mathrm{~mm}$ &
\end{tabular}

represents a probability density function, derived from a particular topographic model, over the space of conceivable values of the measured peak heights, evaluated at the point in that space representing the peak heights that actually were measured. Since we identified 3593 peaks, the space is 3593-dimensional, with each co-ordinate having dimensions of length; hence, a probability density function over this space must have dimensions $1 /(\text { length })^{3593}$. In figure 12, we plot the best-fit theoretical histogram, for comparison with figure 11. (It is the "best fit" out of the peak height probability density functions for which there are elastic contact theories in the literature, not necessarily out of all conceivable probability density functions). Hence, for our mechanical analysis, we take forward a two-step fractal surface topography with the best-fit parameters detailed in table 2 .

\section{What remains now surface topography is known}

To recapitulate, the knowledge of the surface topography we developed in the preceding section leaves us with just two possible mathematical forms for the response to the normal load: an elastic model (equation 
May 20, 2009

\section{Page 15 of 24}

\section{agazine index}

Philosophical Magazine \& Philosophical Magazine Letters

Ice internal friction

201)

$$
f_{e l}=\frac{3^{41 / 9} \pi^{35 / 27} P^{1 / 3} R_{C}^{2 / 3}}{2^{148 / 27} \times 13 E^{26 / 27}} \sigma^{26 / 27}
$$

where

$$
\begin{gathered}
E^{\prime}=\frac{E}{2\left(1-\nu^{2}\right)}, \\
E=\frac{E_{P}}{1+\left(d_{0} / d_{G}\right)\left(1-\exp \left(-\left(\exp \left(-E_{a} /(R \Theta)\right) t_{C} / t_{0}\right)^{p}\right)\right)}
\end{gathered}
$$

$[27,28]$,

$$
\nu=\nu_{0}+\Delta \nu\left(\Theta_{m 0}-\Theta\right)
$$

[32],

$$
t_{C}=\frac{\dot{D} \pm(1) \sqrt{\dot{D}^{2} \pm^{(2)} 2 \hat{Y} R_{C} \ddot{D}}}{\ddot{D}}
$$

with the two \pm signs chosen to give the smallest non-negative value of $t_{C}$, and $\hat{Y}$ is a dimensionless adjustable parameter between $10^{-2}$ and 1 ; and a ductile model (equation 22)

$$
f_{d u}=\left(\frac{G}{\dot{\epsilon}_{n}}\right)^{1 / n} \exp \left(-\frac{E_{a}}{n R \Theta}\right) \sigma
$$

where

$$
\dot{\epsilon}_{n}=\frac{\epsilon_{\star}}{t_{C}}
$$

where $\epsilon_{\star}$ is a dimensionless adjustable parameter between $6 \times 10^{-3}$ and 1 , and the adjustable parameter $\hat{Y}$ remains relevant through $t_{C}$. Additionally, we have three models for the failure of the real contact area: a ductile model (equation 23)

$$
\mathrm{T}_{d u}=\frac{1}{2}\left(\frac{\dot{\epsilon}_{s}}{G}\right)^{1 / n} \exp \left(\frac{E_{a}}{n R \Theta}\right)
$$

where

$$
\dot{\epsilon}_{s}=\frac{\dot{D}}{\hat{Z} R_{C}}
$$

and $\hat{Z}$ is a dimensionless adjustable parameter between $6 \times 10^{-3}$ and 1 ; a brittle model (equation 24)

$$
\mathrm{T}_{b r}=S_{1}\left(\frac{\sigma}{f}\right)^{b}
$$




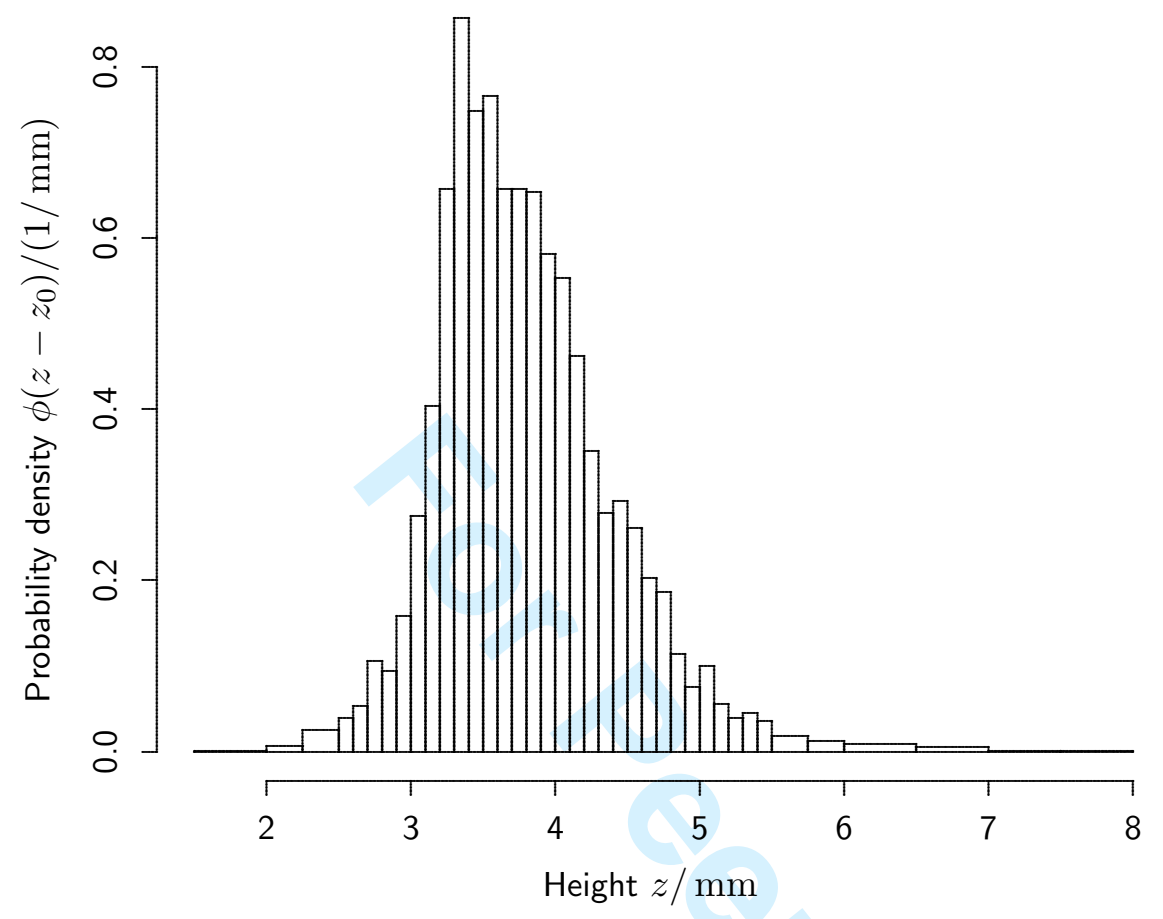

Figure 11. Empirical histogram of peak height distribution.

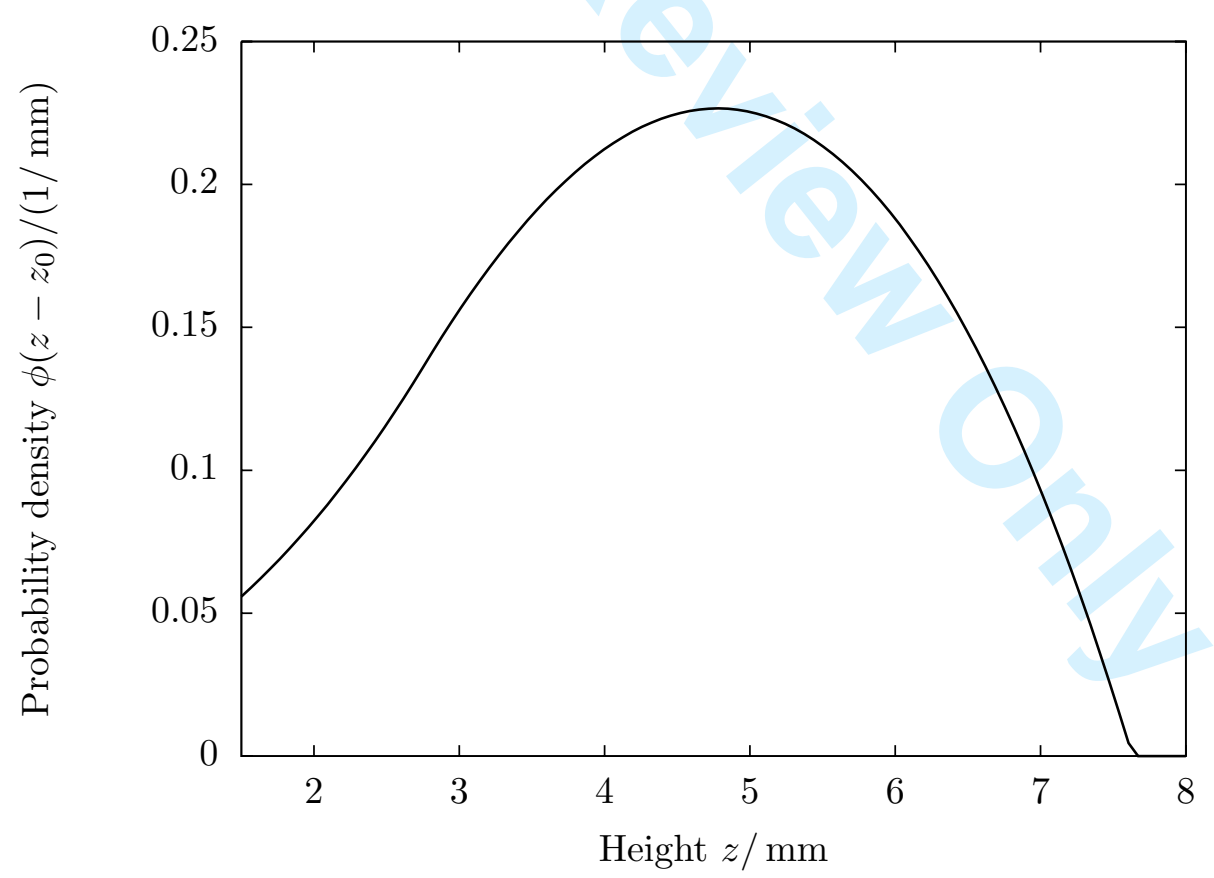

Figure 12. Histogram of two-step fractal peak height distribution with $z_{0}=2.1 \mathrm{~mm}, R_{D}=4.8 \mathrm{~mm}, R_{E}=4.9 \mathrm{~mm}$ (best fit to the empirical data). 


\section{Мау 20,2009 \\ Page 17 of 24

and a melting-lubrication model (equation 25)

$$
\mathrm{T}_{m l}=\frac{\operatorname{sgn}(\dot{D})}{\pi^{1 / 4}\left(\hat{X} R_{C}\right)^{1 / 2}}\left(\frac{\left(\kappa c \rho_{s}\right)^{1 / 2}\left(\Theta_{m}-\Theta\right)}{|\dot{D}|^{1 / 2}}+\left(\frac{\kappa c \rho_{s}\left(\Theta_{m}-\Theta\right)^{2}}{|\dot{D}|}+2 \eta L \rho_{l}|\dot{D}|\right)^{1 / 2}\right),
$$

where (equations 34, 35, 36)

$$
\Theta_{m}=\Theta_{m 0}-C_{C C 1} \frac{\sigma}{f}
$$

or

$$
\Theta_{m}=\Theta_{m 1}+C_{C C 2} \frac{\sigma}{f}
$$

$[30,31]$, whichever is greater, and $\hat{X}$ is a dimensionless adjustable parameter between $10^{-2}$ and 1 .

\section{Unification of the models}

The fact that a material has both elastic/brittle and ductile (and melting-related) mechanical properties does not imply a free choice of how it deforms under a given stress history; it will deform by a mechanism chosen deterministically by the physics. Hence, we propose to unify the models for the response to normal load and the shear failure of the real contact, by a principle of maximum displacement for normal deformation, and of minimum stress for shear failure. That is, we pick the largest value for real contact fraction (equations 39 and 44), and the smallest value for shear strength (equations 46, 48, and 49). Having chosen a unique contact fraction and shear strength, we take their product to predict the sliding shear stress on the fault (equation 1):

$$
\tau=\max \left(f_{e l}, f_{d u}\right) \operatorname{smallest}\left(\mathrm{T}_{d u}, \mathrm{~T}_{b r}, \mathrm{~T}_{m l}\right),
$$

where $\max ()$ means closest to positive infinity and smallest() means closest to zero. This unified model contains all four adjustable parameters, $\hat{X}, \hat{Y}, \hat{Z}$, and $\epsilon_{\star}$.

It is interesting to view these principles for choosing the dominant deformation mechanism from a thermodynamic perspective. In the case of the maximum-displacement principle for the normal deformation, this is straightforward. Maximizing the displacement of the pieces of ice towards each other, and therefore maximizing the real contact fraction, leads to the greatest possible work being done on the ice (and eventually converted to heat) by the external free energy reservoir that applies the normal stress; this embodies the availability minimization principle of equilibrium thermodynamics. More formally, it is reasonable to assume that the two possible states will undergo about the same degree of elastic recovery on removal of the stress, and hence that they have approximately the same Helmholtz free energy. It is also reasonable to assume them to be at the same temperature, due to contact with surrounding brine and/or air. In situations of constant Helmholtz free energy and temperature, the appropriate availability function to minimize for thermodynamic equilibrium is simply the volume [52, p. 110]. Minimal volume is achieved by maximizing the (convergent) normal displacement.

For shear failure, the situation is more complicated. As long as the velocity and shear stress are nonzero, work continues to be done. Therefore, within the duration of the processes of interest, the shear displacement degree of freedom never reaches thermodynamic equilibrium. In this case, the appropriate thermodynamic principle is not availability minimization but the kinetic rate equation (cf. [53, pp. 391392, 436-439]). In supplementary online material $\mathrm{H}$, we discuss how the kinetic rate equation leads to the principle of minimum shear stress.

We note in passing that our approach, of treating the dimensionless contact-breaking displacement $\hat{Y}$, the dimensionless shear layer thickness $\hat{Z}$, and the typical normal asperity strain $\epsilon_{\star}$ as adjustable parameters 


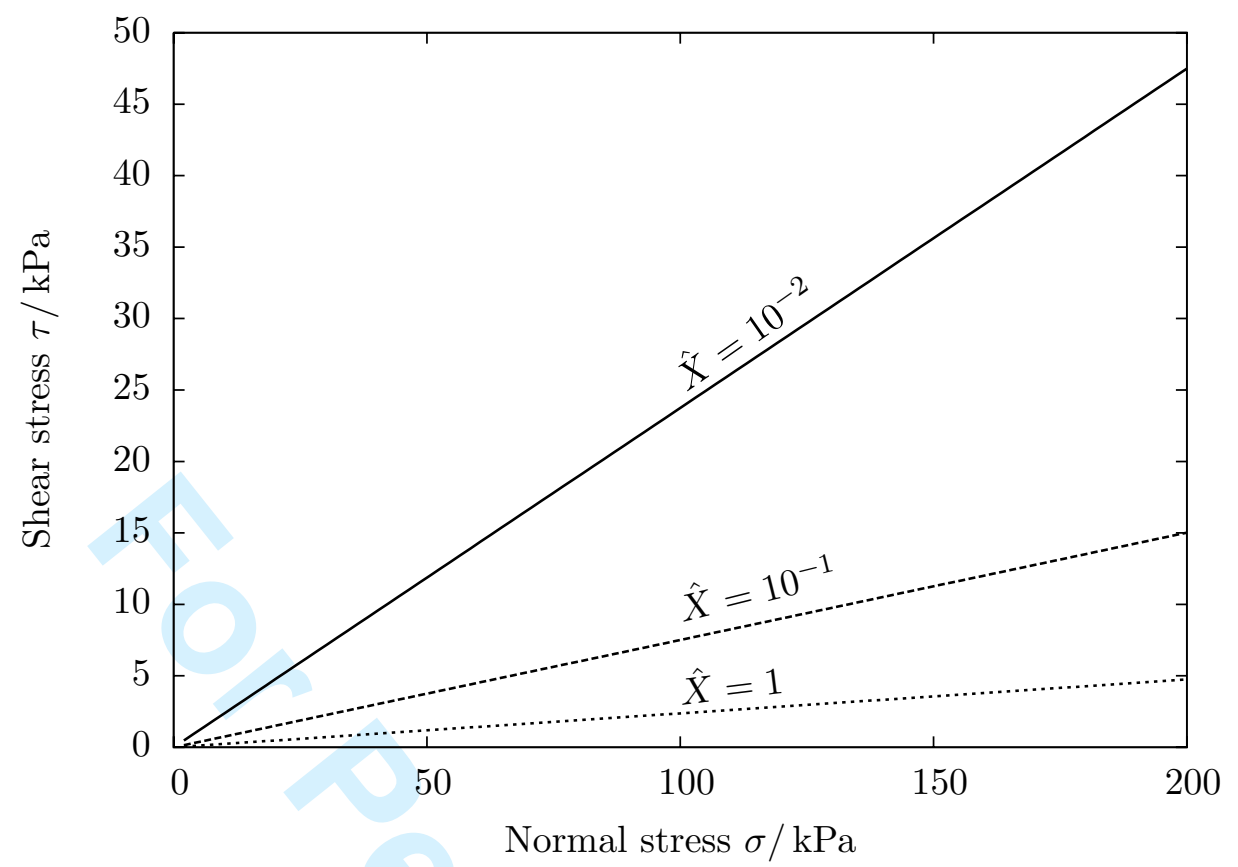

Figure 13. Sliding shear stress as function of normal stress. Three curves shown, corresponding to different values of dimensionless melt-water expulsion displacement $\hat{X}$. Other adjustable parameters fixed: dimensionless contact-breakage displacement $\hat{Y}=10^{-1}$, dimensionless shear layer thickness $\hat{Z}=10^{-1 / 2}$, asperity normal strain $\epsilon_{\star}=8 \times 10^{-2}$. Sliding velocity fixed: $\dot{D}=5.4563$ mm/ s.

for fitting to friction measurements, is not the only conceivable approach; it might, in principle, be possible to measure $\hat{Y}, \hat{Z}$, and $\epsilon_{\star}$ independently, by some method such as time-resolved imaging of processes at individual asperities with neutron scattering.

\section{Results}

We are now in a position to plot quantitative predictions of our unified ice internal friction model, for the sliding shear stress as a function of normal stress on the fault (figures 13 15]) and of sliding velocity (figures 16-18). Each plot additionally shows the effects of varying one of the four adjustable parameters. However, since we have not found any circumstances where the minimum stress principle selects ductile shear failure (section 8), $\hat{Z}$ is irrelevant to the results, and we do not show the effects of varying this parameter. Throughout, the temperature is fixed at $\Theta=268.91 \mathrm{~K}$ and the sliding acceleration at $\ddot{D}=325 \mu \mathrm{m} / \mathrm{s}^{2}$.

In addition, we show some illustrative values for shear stress as a function of temperature (figure 19) and of acceleration (figure 20]).

\section{Discussion}

In all circumstances encompassed by the above plots, the maximum displacement algorithm chooses the ductile response to normal load.

In most circumstances, the minimum shear stress algorithm chooses the melting-lubrication shear failure mode. This exhibits a maximum in the shear stress as a function of velocity, at moderately low sliding speeds $\left(\hat{X} \in\left\{10^{-1}, 1\right\}\right.$, figure [16, $\hat{Y} \in\left\{10^{-1}, 1\right\}$, figure [17, $\epsilon_{\star} \in\left\{6 \times 10^{-3}, 8 \times 10^{-2}\right\}$, figure [18). In some cases, this peak is so high that the algorithm switches to the brittle shear failure mode at (moderately) low sliding speeds $\left(\hat{Y}=10^{-2}\right.$, figure [17, $\epsilon_{\star}=1$, figure 18), producing a characteristic " $L_{L}$ " shape which bears a striking qualitative resemblance to the empirical data sets at similar temperatures presented by Kennedy et al. [13]. We take this resemblance to suggest that our model is a reasonable description of real frictional behaviour. In one case, at even lower sliding speeds, the low-speed shoulder of the peak in 


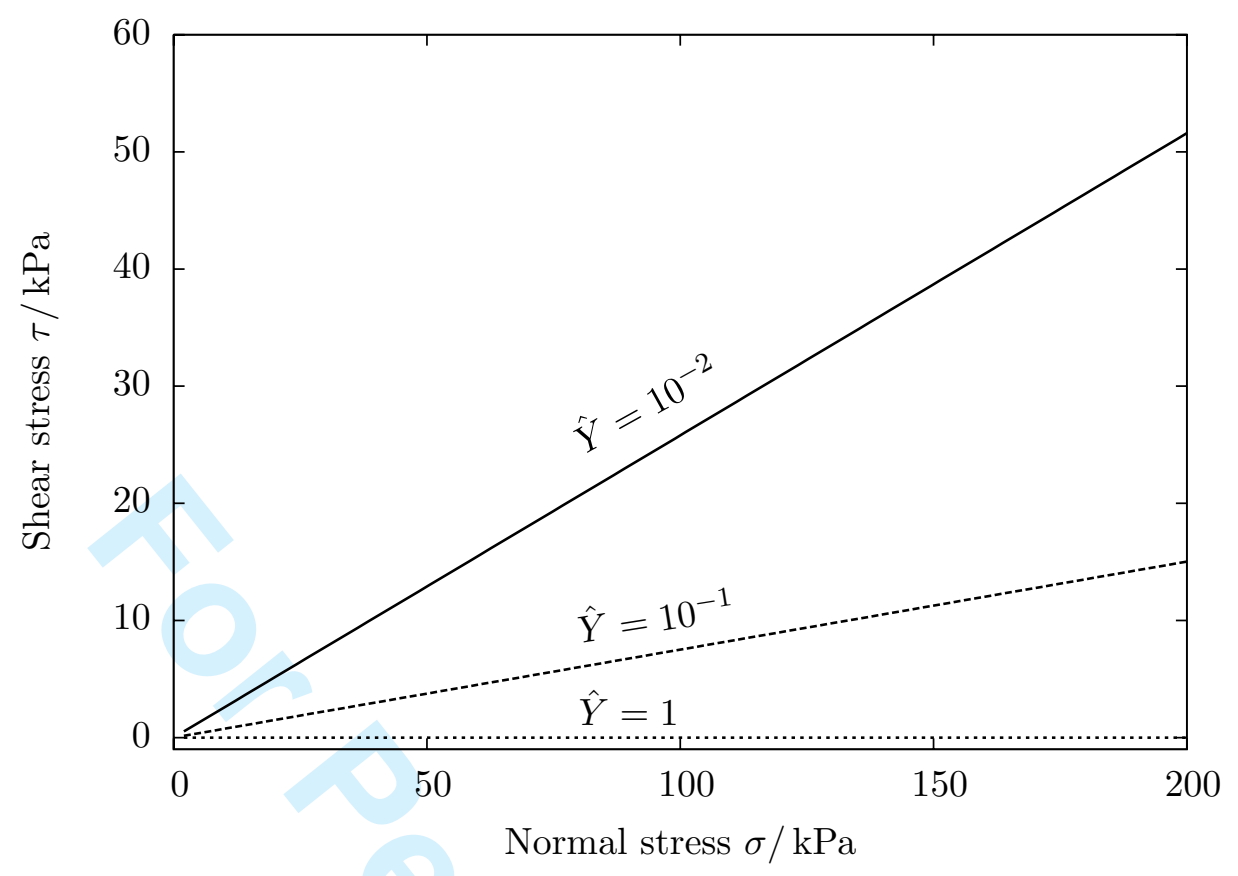

Figure 14. Sliding shear stress as function of normal stress. Three curves shown, corresponding to different values of dimensionless contact-breakage displacement $\hat{Y}$. Other adjustable parameters fixed: dimensionless melt-water expulsion displacement $\hat{X}=10^{-1}$, dimensionless shear layer thickness $\hat{Z}=10^{-1 / 2}$, asperity normal strain $\epsilon_{\star}=8 \times 10^{-2}$. Sliding velocity fixed: $\dot{D}=5.4563$ mm/ s.

melting-lubrication shear stress allows melting-lubrication to regain control $\left(\hat{X}=10^{-2}\right.$, figure 16).

The values of the adjustable parameters $\hat{X}, \hat{Y}$, and $\epsilon_{\star}$ make enough difference to the shear stress predictions to be readily inferred from empirical data. $\hat{Z}$, on the other hand, makes no discernible difference to the predictions. This is unsurprising, given that the algorithm never selects the ductile shear failure mechanism.

The sliding shear stress is a non-linear function of velocity. This means that one must be very wary of taking temporal or spatial averages over periods or regions over which the velocity changes significantly, which will lead to systematic over- or under-estimation of the shear stress (cf. [51, p. 35]). In particular, Yoshioka [54] has noted that, where the displacement since the last time the material stopped moving is small compared with the contact-breaking distance $Y$, this can invalidate the procedure of averaging over an area that contains several asperities; hence, our model can be expected to break down when the displacement since the last time the material stopped moving is very small.

The velocity-dependence of sliding shear stress in our model becomes particularly strong at small velocities. Hence, the shear stress at zero velocity is very different from the shear stress at a small, non-zero velocity. In this sense, our model exhibits a self-organized distinction between static and dynamic friction.

\section{Conclusions}

The unusual rheology of ice introduces velocity- and acceleration- dependences, as well as a number of mechanical and topographic parameters, into standard micro-mechanical theories of friction. A principle of maximum displacement for normal deformation, and of minimum stress for shear failure allows the unification of the various standard micro-mechanical theories of friction for ice into a single model with four dimensionless adjustable parameters. The four parameters represent, for a typical asperity contact, the sliding distance required to expel melt-water $(\hat{X}$, non-dimensionalized with the asperity radius of curvature), non-dimensionalized with), the sliding distance required to break contact $(\hat{Y}$, non-dimensionalized with the asperity radius of curvature), the normal strain in the asperity $\left(\epsilon_{\star}\right)$, and the thickness of any ductile shear zone $(\hat{Z}$, non-dimensionalized with the asperity radius of curvature). The maximum displacement 


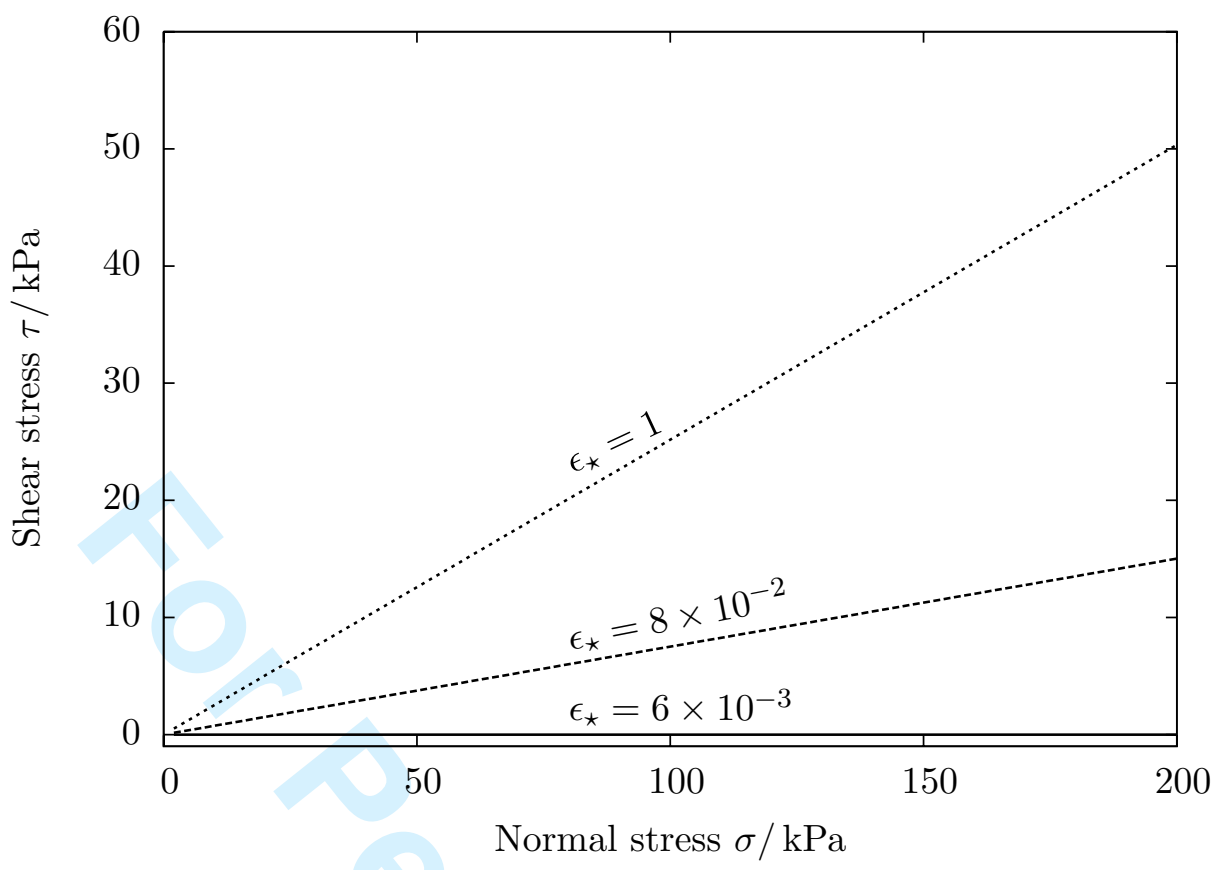

Figure 15. Sliding shear stress as function of normal stress. Three curves shown, corresponding to different values of asperity normal strain $\epsilon_{\star}$. Other adjustable parameters fixed: dimensionless melt-water expulsion displacement $\hat{X}=10^{-1}$, dimensionless contact-breakage displacement $\hat{Y}=10^{-1}$, dimensionless shear layer thickness $\hat{Z}=10^{-1 / 2}$. Sliding velocity fixed: $\dot{D}=5.4563 \mathrm{~mm} / \mathrm{s}$.

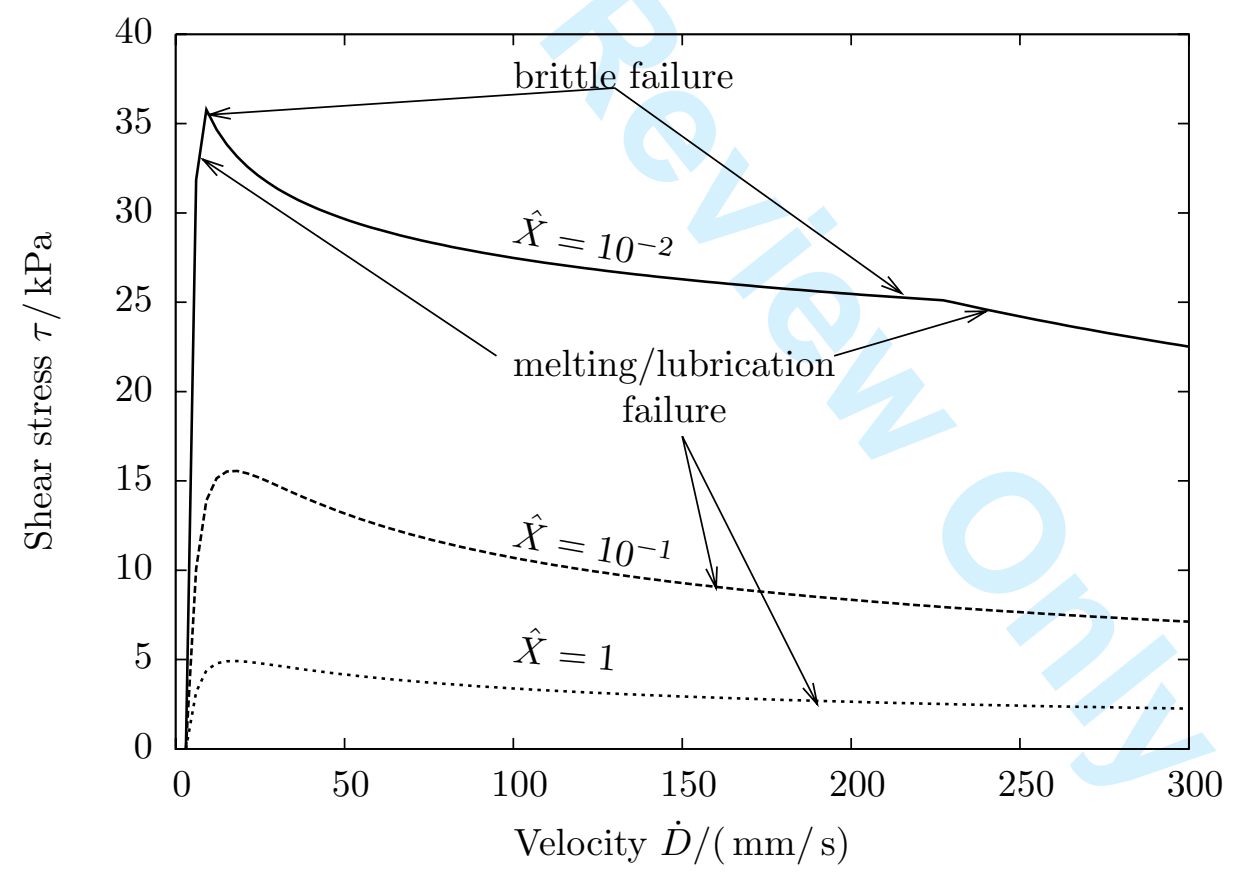

Figure 16. Sliding shear stress as function of sliding velocity. Three curves shown, corresponding to different values of dimensionless melt-water expulsion displacement $\hat{X}$. Other adjustable parameters fixed: dimensionless contact-breakage displacement $\hat{Y}=10^{-1}$, dimensionless shear layer thickness $\hat{Z}=10^{-1 / 2}$, asperity normal strain $\epsilon_{\star}=8 \times 10^{-2}$. Normal stress fixed: $\sigma=113.9 \mathrm{kPa}$. Changes in the shear failure mechanism selected by the minimum shear stress algorithm are manifested as discontinuities in the gradient of the curves. Specifically, on the $\hat{X}=10^{-2}$ curve, shear failure is by melting and lubrication for $\dot{D} \lesssim 7.2 \mathrm{~mm} / \mathrm{s}$ and for $\dot{D} \gtrsim 227.8 \mathrm{~mm} / \mathrm{s}$, and by brittle fracture for $7.2 \mathrm{~mm} / \mathrm{s} \lesssim \dot{D} \lesssim 227.8 \mathrm{~mm} / \mathrm{s}$. On the $\hat{X} \in\left\{10^{-1}, 1\right\}$ curves, shear failure is by melting and lubrication throughout. 


\section{ay 20,2009 \\ Page 21 of 24

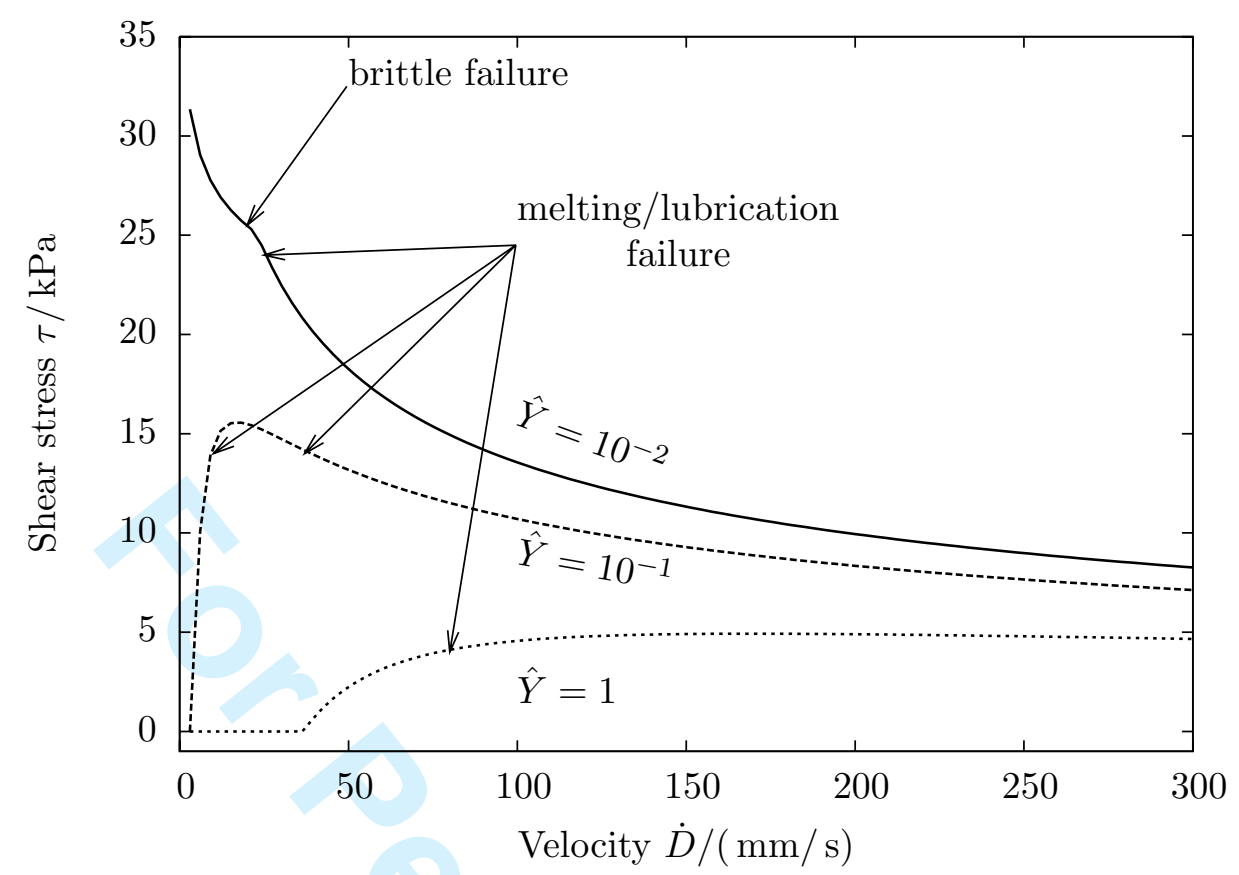

Figure 17. Sliding shear stress as function of sliding velocity. Three curves shown, corresponding to different values of dimensionless contact-breakage displacement $\hat{Y}$. Other adjustable parameters fixed: dimensionless melt-water expulsion displacement $\hat{X}=10^{-1}$, dimensionless shear layer thickness $\hat{Z}=10^{-1 / 2}$, asperity normal strain $\epsilon_{\star}=8 \times 10^{-2}$. Normal stress fixed: $\sigma=113.9 \mathrm{kPa}$. Changes in the shear failure mechanism selected by the minimum shear stress algorithm are manifested as discontinuities in the gradient of the curves. Specifically, on the $\hat{Y}=10^{-2}$ curve, shear failure is by melting and lubrication for $\dot{D} \lesssim 1.1 \mathrm{~mm} / \mathrm{s}$ and for $\dot{D} \gtrsim 22.7 \mathrm{~mm} / \mathrm{s}$, and by brittle fracture for $1.1 \mathrm{~mm} / \mathrm{s} \lesssim \dot{D} \lesssim 22.7 \mathrm{~mm} / \mathrm{s}$. On the $\hat{Y} \in\left\{10^{-1}, 1\right\}$ curves, shear failure is by melting and lubrication throughout.

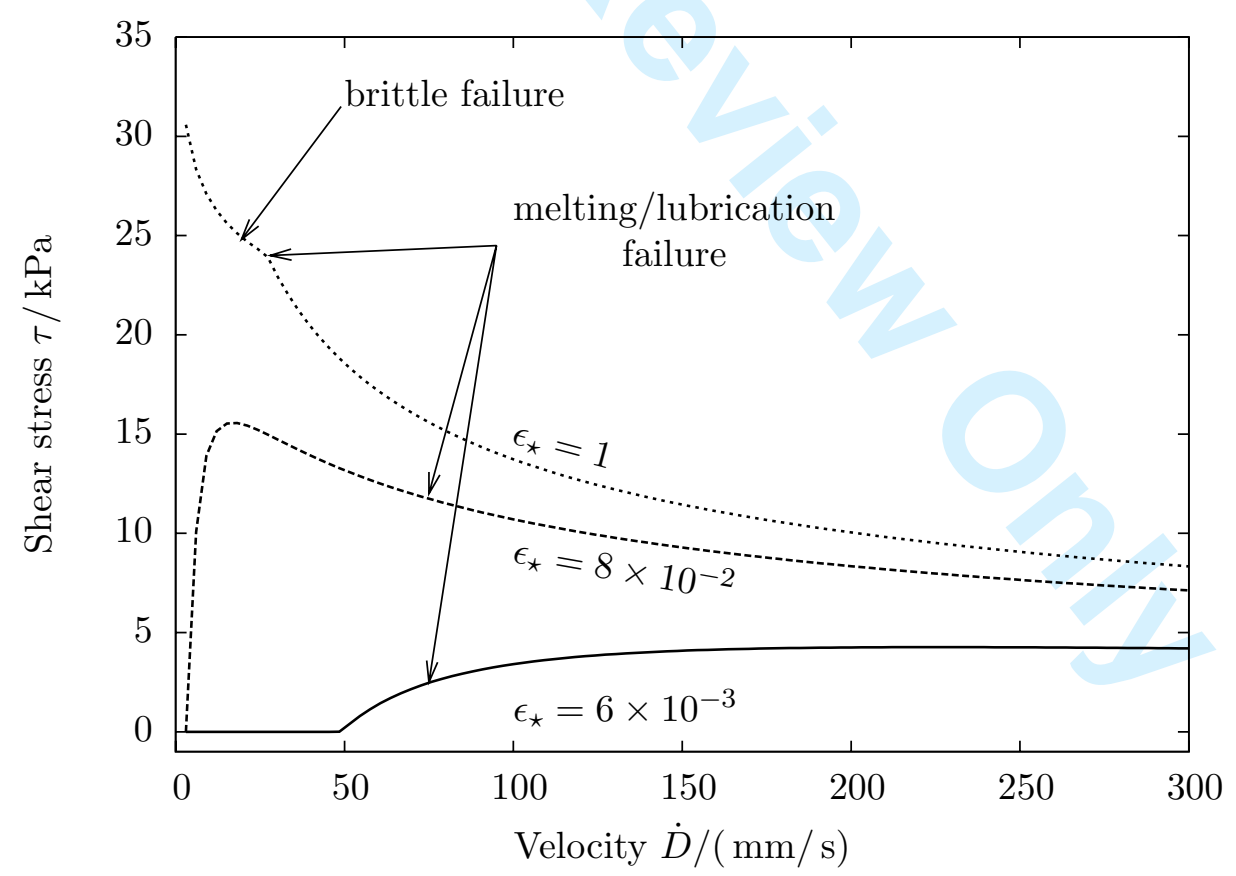

Figure 18. Sliding shear stress as function of sliding velocity. Three curves shown, corresponding to different values of asperity normal strain $\epsilon_{\star}$. Other adjustable parameters fixed: dimensionless melt-water expulsion displacement $\hat{X}=10^{-1}$, dimensionless contact-breakage displacement $\hat{Y}=10^{-1}$, dimensionless shear layer thickness $\hat{Z}=10^{-1 / 2}$. Normal stress fixed: $\sigma=113.9 \mathrm{kPa}$. Changes in the shear failure mechanism selected by the minimum shear stress algorithm are manifested as discontinuities in the gradient of the curves. Specifically, on the $\epsilon_{\star}=1$ curve, shear failure is by melting and lubrication for $\dot{D} \lesssim 0.6 \mathrm{~mm} / \mathrm{s}$ and for $\dot{D} \gtrsim 27.2 \mathrm{~mm} / \mathrm{s}$, and by brittle fracture for $0.6 \mathrm{~mm} / \mathrm{s} \lesssim \dot{D} \lesssim 27.2 \mathrm{~mm} / \mathrm{s}$. On the $\epsilon_{\star} \in\left\{6 \times 10^{-3}, 8 \times 10^{-2}\right\}$ curves, shear failure is by melting and lubrication throughout. 


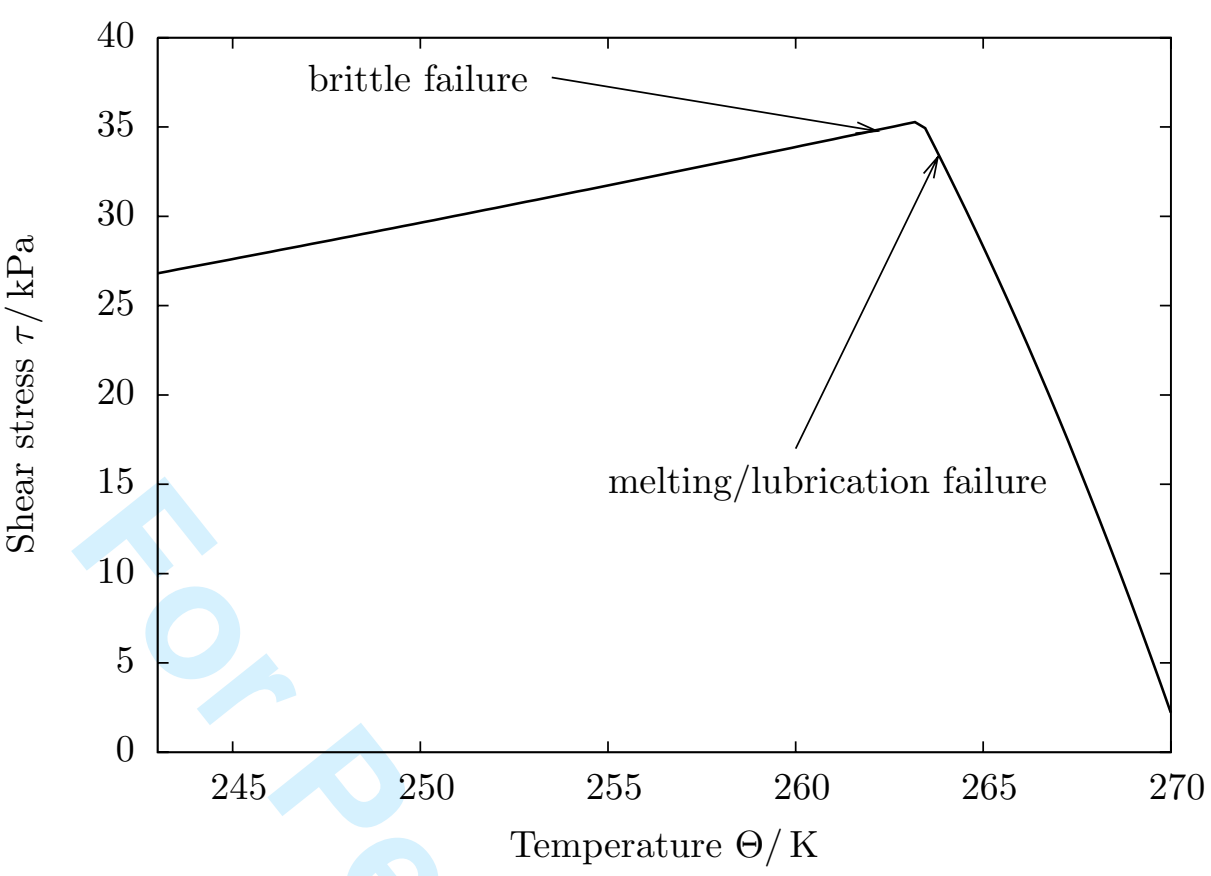

Figure 19. Sliding shear stress as function of temperature. Adjustable parameters fixed: dimensionless melt-water expulsion displacement $\hat{X}=10^{-1}$, dimensionless contact-breakage displacement $\hat{Y}=10^{-1}$, dimensionless shear layer thickness $\hat{Z}=10^{-1 / 2}$, asperity normal strain $\epsilon_{\star}=8 \times 10^{-2}$. Normal stress fixed: $\sigma=113.9 \mathrm{kPa}$. Sliding velocity fixed: $\dot{D}=5.4563 \mathrm{~mm} / \mathrm{s}$. Acceleration fixed:

$\ddot{D}=325 \mu \mathrm{m} / \mathrm{s}^{2}$. A change in the shear failure mechanism selected by the minimum shear stress algorithm is manifested as a discontinuity in the gradient of the curve. Specifically, shear failure is by melting and lubrication for $\Theta \gtrsim 263.4 \mathrm{~K}$, and by brittle fracture for $\Theta \lesssim 263.4 \mathrm{~K}$.

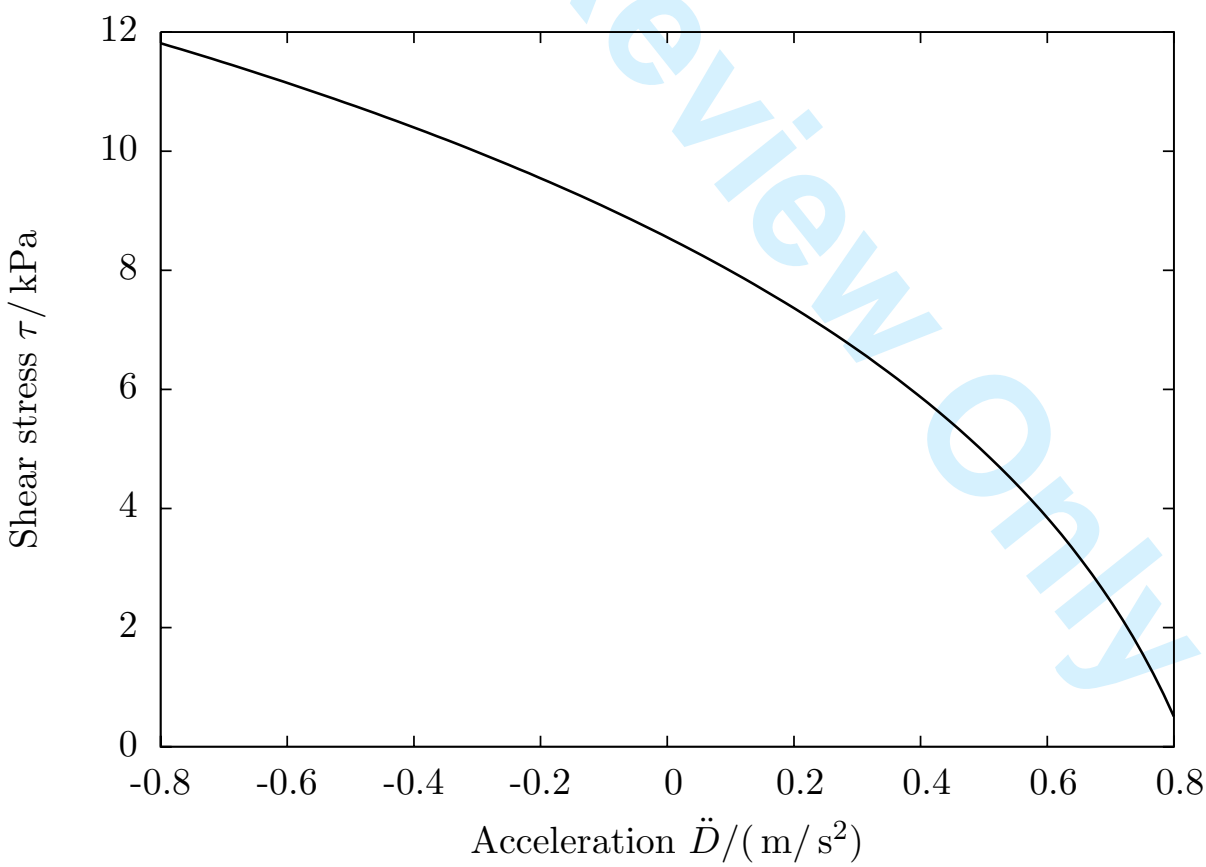

Figure 20. Sliding shear stress as function of acceleration. Adjustable parameters fixed: dimensionless melt-water expulsion displacement $\hat{X}=10^{-1}$, dimensionless contact-breakage displacement $\hat{Y}=10^{-1}$, dimensionless shear layer thickness $\hat{Z}=10^{-1 / 2}$, asperity normal strain $\epsilon_{\star}=8 \times 10^{-2}$. Normal stress fixed: $\sigma=113.9 \mathrm{kPa}$. Sliding velocity fixed: $\dot{D}=5.4563 \mathrm{~mm} / \mathrm{s}$. Temperature fixed: $\Theta=268.91 \mathrm{~K}$ 


\section{ay 20, 2009

principle implies ductile deformation of the ice under normal load, and the minimum shear stress principle implies shear failure that proceeds mostly by melting-lubrication, although some parameter values lead to brittle failure at low-moderate sliding speeds. One of the four adjustable parameters $(\hat{Z})$ is essentially irrelevant to the internal frictional behaviour of ice, relating as it does to the redundant possibility of ductile shear failure. The other three adjustable parameters are capable of being readily inferred from experimental data.

\section{Acknowledgements}

The authors would like to thank the Hamburg Ship Model Basin (HSVA), especially the ice tank crew, for the hospitality, technical support and professional execution of the test programme in the ARCTECLAB. The access to the Research Infrastructure ARCTECLAB was financially supported within the 5th Framework Programme by the "Improving Human Potential"- Programme, (IHP), from the European Union through contract HPRI-CT-2001-00126.

We would like to thank the Natural Environment Research Council, and the Joint Infrastructure Fund, in the UK, for financial support.

DLF and DCH acknowledge financial support made available from the Leverhulme Trust.

DCH acknowledges financial support from Rio Tinto.

We are grateful to Eddie Benbow, Steve Boon, John Bowles, Neil Hughes, and Richard Rabe, at University College London, for engineering support during the experimental aspects of this project.

Thanks are also due to Kaj Riska, Topi Leiviskä, Pentti Tukia, Juha Alasoini, and Jukka Tuhkuri, at Helsinki University of Technology, for hospitality, helpful discussions, and experimental assistance during the programme of experiments mentioned in supplementary online material D.

We thank Sérgio H. Faria for helpful and detailed comments in review of this paper.

\section{References}

[1] P. D. Taylor, D. L. Feltham, P. R. Sammonds et al., J. Geophys. Res. 111 C11015 (November 2006).

[2] P. Oksanen, Coefficient of Friction between Ice and Some Construction Materials, Plastics and Coatings, 7 (Valtion Teknillnen Tutkimuskeskus, Espoo, 1980).

[3] P. Oksanen and J. Keinonen, Wear 78315 (1982).

[4] W. B. Durham, H. C. Heard and S. H. Kirby, J. Geophys. Res. 88 B377 (November 1983).

[5] P. Oksanen, Friction and Adhesion of Ice, 10 (Valtion Teknillnen Tutkimuskeskus, Espoo, 1983).

[6] M. L. Beeman, W. B. Durham and S. H. Kirby, J. Geophys. Res. 937625 (July 1988).

[7] D. E. Jones, F. E. Kennedy and E. M. Schulson, Ann. Glaciol. 15242 (1991).

[8] M. A. Rist, S. J. Jones and T. D. Slade, Ann. Glaciol. 19131 (1994).

[9] M. A. Rist, J. Phys. Chem. B 1016263 (August 1997).

[10] J. Tuhkuri and M. Lensu, Ice Tank Tests on Rafting of a Broken Ice Field, M-218 (Helsinki University of Techology, Otaniemi, 1997).

[11] P. R. Sammonds, S. A. F. Murrell and M. A. Rist, J. Geophys. Res. 10321795 (September 1998).

[12] J. Tuhkuri and M. Lensu, Ice Tank Tests on Ridging of Non-Uniform Ice Sheets, M-236 (Helsinki University of Technology, Espoo, 1998).

[13] F. E. Kennedy, E. M. Schulson and D. E. Jones, Philos. Mag. A 801093 (May 2000).

[14] P. R. Sammonds, D. C. Hatton, D. L. Feltham et al., in Proceedings of the 18th International Conference on Port and Ocean Engineering Under Arctic Conditions, Clarkson University (Clarkson University, Potsdam, New York, 2005), volume 1, pp. 303-312, link: PRS05]

[15] E. M. Schulson, A. L. Fortt, D. Iliescu et al., Acta Mater. 543923 (September 2006).

[16] E. M. Schulson, A. L. Fortt, D. Iliescu et al., J. Geophys. Res. 111 C11S25 (October 2006).

[17] J. Weiss, E. M. Schulson and H. L. Stern, Earth Planet. Sci. Lett. 2551 (March 2007).

[18] F. P. Bowden and L. Leben, Proc. R. Soc. Lond. A 169371 (February 1939).

[19] J. F. Archard, J. Appl. Phys. 24981 (August 1953).

[20] J. A. Greenwood and J. B. P. Williamson, Proc. R. Soc. Lond. A 295300 (December 1966).

[21] J. A. F. Gerrard, M. F. Perutz and A. Roch, Proc. R. Soc. Lond. A 213546 (July 1952).

[22] M. A. Rist and S. A. F. Murrell, J. Glaciol. 40305 (1994).

[23] L. D. Landau, E. M. Lifshitz and L. P. ]Pitaevskiı̆, Fluid Mechanics, volume 6 of Landau and Lifshitz Course of Theoretical Physics (Butterworth-Heinemann, Oxford, 1987 (1959)), second English edition, translated from the Russian by J. B. Sykes and W. H. Reid.

[24] J. R. Rice, J. Geophys. Res. 111 B05311 (May 2006).

[25] A. W. Rempel and J. R. Rice, J. Geophys. Res. 111 B09314 (September 2006).

[26] J. W. Glen, Proc. R. Soc. Lond. A 228519 (March 1955).

[27] N. K. Sinha, Exp. Mech. pp. 464-470 (December 1978).

[28] T. J. O. Sanderson, Ice Mechanics: Risks to Offshore Structures (Graham \& Trotman, London, 1988).

[29] O. Reynolds, Mem. Proc. Manch. Lit. Philos. Soc. 43 (1899), URL: http://gallica.bnf.fr/scripts/ConsultationTout.exe?0=0099470\&E=00000749

[30] F. P. Bowden and T. P. Hughes, Proc. R. Soc. Lond. A 172280 (August 1939). 
[31] M. Chaplin, Phase diagram of water and ice, World-Wide Web page (January 2006), URL: http://www.lsbu.ac.uk/water/phase.html .

[32] N. K. Sinha, Cold Reg. Sci. Technol. 17127 (December 1989).

[33] B. W. Petley, in Noyes et al. [57], chapter 1.2.3, URL: hhttp://www.kayelaby.npl.co.uk/units_and_fundamental_constants/1_2/1_2_3.html .

[34] D. L. Hall, S. M. Sterner and R. J. Bodnar, Econ. Geol. 83197 (January-February 1988).

[35] R. Morrell, in Noyes et al. [57], chapter 2.3.7, pp. 81-94, URL: $\{$ http://www.kayelaby.npl.co.uk/general_physics/2_3/2_3_7.html .

[36] M. J. Richardson, in Noyes et al. [57], chapter 2.3.6, pp. 76-81, URL: 〈http://www .kayelaby.npl.co.uk/general_physics/2_3/2_3_6.html .

[37] S. L. Lewis[Peggs], in Noyes et al. [57], chapter 2.2.1, pp. 41-43, URL: \{http://www.kayelaby.npl.co.uk/general_physics/2_2/2_2_1.html\}.

[38] M. L. McGlashan, in Noyes et al. [57], chapter 3.6, pp. 266-271, originally compiled by G. W. C. Kaye O.B.E., M.A., D.Sc., F.R.S. and T. H. Laby M.A., Sc.D., F.R.S.; now prepared under the direction of an editorial committee. URL: http://www.kayelaby.npl.co.uk/,

[39] J. T. R. Watson, in Noyes et al. [57], chapter 2.2.3, URL: http://www.kayelaby.npl.co.uk/general_physics/2_2/2_2_3.html .

[40] M. L. McGlashan, in Noyes et al. [57], chapter 3.10, pp. 338-357, originally compiled by G. W. C. Kaye O.B.E., M.A., D.Sc., F.R.S. and T. H. Laby M.A., Sc.D., F.R.S.; now prepared under the direction of an editorial committee. URL: http://www.kayelaby.npl.co.uk/,

[41] J. F. Archard, Proc. R. Soc. Lond. A 243190 (December 1957).

[42] F. P. Bowden and D. Tabor, Proc. R. Soc. Lond. A 169391 (February 1939).

[43] F. P. Bowden and D. Tabor, Friction and Lubrication, Metheun's Physical Monographs (Metheun \& Company, London, 1967 (1950)), revised reprint edition.

[44] J. Y. Chen, Y. Wei, Y. Huand et al., Eng. Fract. Mech. 64625 (November 1999).

[45] J. W. Hutchinson, Int. J. Solids Struct. 37225 (January 2000).

[46] Microset Products, Nuneaton, Microset UK: Engineering Replication Materials, Silicone/Polymer Replication, Surface Inspection Materials (February 2003), URL: 〈http://www.microset.co.uk/media/index.html).

[47] Proscan 2000, World-Wide Web page, URL: \{http://www.scantron-net.co.uk/proscan2000.htm].

[48] D. R. Scott, C. J. Marone and C. G. Sammis, J. Geophys. Res. 997231 (April 1994).

[49] D. J. C. MacKay, Neural Comput. 4415 (May 1992), URL: http://www.inference.phy.cam.ac.uk/mackay/inter.nc.ps.gz .

[50] H. Jeffreys, Theory of Probability, The International Series of Monographs on Physics (Clarendon Press, Oxford, 1961 (1939)), third edition.

[51] D. J. C. MacKay, Information Theory, Inference, and Learning Algorithms (Cambridge University Press, Cambridge, 2003), URL: http://www.inference.phy.cam.ac.uk/itprnn/book.pdf .

[52] C. J. Adkins, Equilibrium Thermodynamics (Cambridge University Press, Cambridge, 1983 (1968)), third edition.

[53] A. J. Walton, Three Phases of Matter, Oxford Science Publications (Clarendon Press, Oxford, 1983 (1976)), second edition.

[54] N. Yoshioka, Tectonophysics 27729 (August 1997).

[55] Scantron Industrial Products, Taunton, Proscan 2000: System Technical Specification, URL: http://www.scantron-net.co.uk/pdf/Proscan_2000_Tech.pdf .

[56] G. L. Squires, Practical Physics (Cambridge University Press, Cambridge, 2001 (1968)), fourth edition.

[57] J. G. Noyes, J. Asher, O. C. Jones et al. (Editors), Kaye \& Laby: Tables of Physical and Chemical Constants (Longman, Harlow, 1995 (1911)), sixteenth edition, originally compiled by G. W. C. Kaye O.B.E., M.A., D.Sc., F.R.S. and T. H. Laby M.A., Sc.D., F.R.S.; now prepared under the direction of an editorial committee. URL: $\langle$ http://www.kayelaby.npl.co.uk//.

[58] L. D. Landau, E. M. Lifshitz, A. M. Kosevich et al., Theory of Elasticity, volume 7 of Landau and Lifshitz Course of Theoretical Physics (Elsevier Butterworth-Heinemann, Oxford, 1986 (1959)), third English edition, translated by J. B. Sykes and W. H. Reid.

[59] H.-O. Peitgen, H. Jürgens and D. Saupe, Chaos and Fractals: New Frontiers of Science (Springer-Verlag, New York, 1992).

[60] D. Crawford, gnuplot (December 1998), URL: 〈http://www.ucc.ie/gnuplot/gnuplot.html]. 